\title{
Light Filters for Eye Protection
}

This content has been downloaded from IOPscience. Please scroll down to see the full text. 1917 Trans. Opt. Soc. 1873

(http://iopscience.iop.org/1475-4878/18/3/301)

View the table of contents for this issue, or go to the journal homepage for more

Download details:

IP Address: 131.170.6.51

This content was downloaded on 20/08/2015 at 04:00

Please note that terms and conditions apply. 


\title{
Light Filters for Eye Protection.
}

\author{
By L. C. MARTIN, A.R.C.Sc., D.I.C., B.Sc., Imperial College \\ of Science and Technology.
}

Read and Discussed 12th April, 1917.

INDUSTRIAL developments, together with a great increase of travel, have of late years led to the necessity of seeking means to protect the eyes from the effects of intense or trying illumination. Glass workers and others find a necessity for such protection, as does the traveller in the glare of tropical sunlight. Investigations have been carried out to determine the causes of deleterious effects observed in particular cases, and many special glasses and light filters have been described for the mitigation of glare and strain. The present paper seeks to summarise the main results obtained, together with the considerations necessary in providing for particular circumstances, and also submits a series of spectrophotometric measurements on certain protective glasses and substitutes for glass.

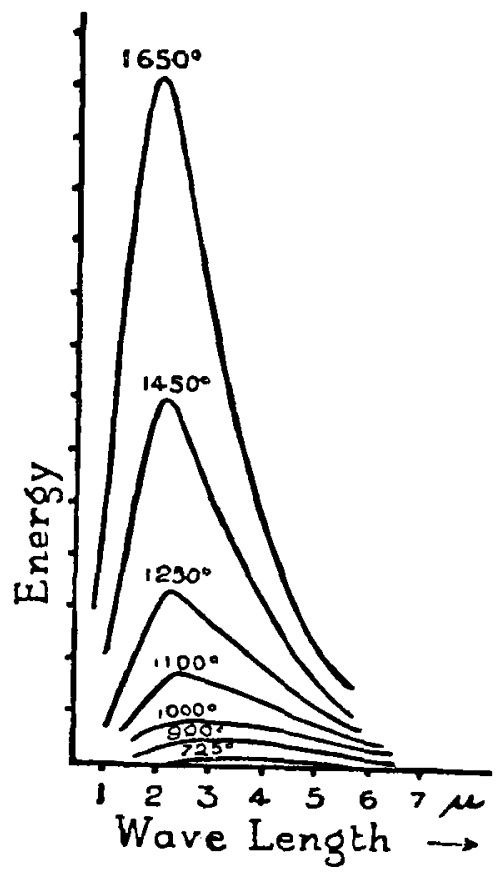

FiG. 1.

Radiation.-A heated body when placed in space would become cold by reason of Radiation. According to the wave-theory, this action takes place by means of wave motions in the ether, and it is the wavelength or the frequency which determines the characteristics of the radiation. The shortest known waves are the X-rays, and with increasing wave-length come the ultra-violet, visible, infra-red, and lastly the electric waves used in wireless telegaphy.

Certain problems arise in screening the eyes from parts of the radiation emitted by heated bodies at various temperatures. The distribution of energy with wavelength, in the spectrum given by a full radiator, has been experimentally determined by Lummer and Pringsheim'. The wave-length corresponding to maximum energy, $\lambda_{m}$, is a function of the temperature, $T$, as are also the total energy emitted, $E$, and the energy at any particular wave-length, $E_{\lambda}$. 
The formulæ are :-

$$
\begin{aligned}
\lambda_{m} \mathrm{~T} & =\text { constant }=2930 \text { approximately } \\
\mathrm{E} & =c \mathrm{~T}^{4} \\
\mathrm{E} & =\frac{c_{\mathrm{r}} \lambda^{-5}}{\left(e^{c_{2} / \lambda} \mathrm{T}-1\right)} \text { where } c, c_{1}, \text { and } c_{2} \text { are constants. }
\end{aligned}
$$

They have been theoretically derived, and agree fairly well with experimental data. They apply to full radiators only. In the case of substances giving bright line emission spectra, the maximum energy may, under certain conditions, lie in the ultra violet, as has been shown by Pfluger for the case of the condensed electric discharge between zinc electrodes. We have no evidence for believing, however, that the exceedingly high temperature, which such a condition would indicate if the emitting substance were a full radiator, has been attained.

For melting glass at a temperature of $1400^{\circ} \mathrm{C}$., say (absolute temperature at $1670^{\circ}$ approximately), we shall have

For a Nernst glower

$$
\lambda_{m}=\frac{2930}{1670}=1 \cdot 75 \mu
$$

$$
\text { Temp. }=2200^{\circ} \mathrm{C} \cdot \lambda_{m}=1 \cdot 2 \mu
$$

The point of maximum energy in the spectrum will thus lie far in the infra-red till very high temperatures are reached. The energy curve for sunlight has been experimentally determined by Langley ${ }^{2}$. One of his

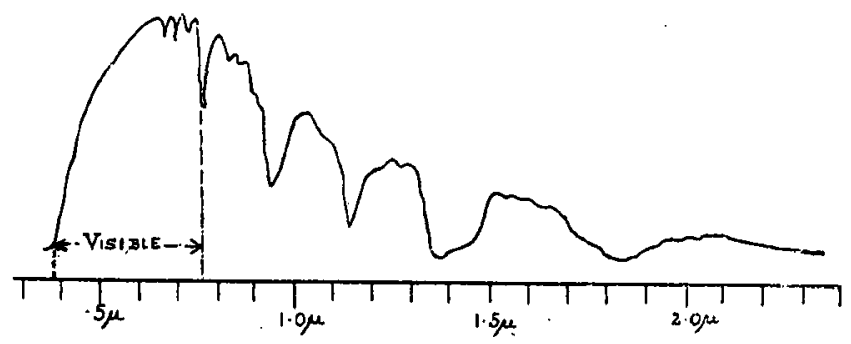

LANG!EY'S NORMAL SOLAR SPECTRUM.

Fic. 2.

early results is shown. A great deal of work has been accomplished on this subject by the Smithsonian Institution. In the visible spectrum the Fraunhofer lines provide convenient points for reference. Wavelength is measured in terms of the unit $\mu$. which is equal to $10^{-4} \mathrm{cms}$. The Angström unit sometimes used for the visible spectrum is $10^{-8} \mathrm{cms}$. For the sake of consistency we shall use the unit $\mu$ throughout the present paper. 
"Schumann", waves

Shortest solar waves reaching earth..

Ordinary glass transmits about ..

Crookes

"Shorter "'limit of visibility about "

Violet region

Blue

Green

Yellow

Red

"Longer "'limit of visibility

Infra-red known waves

Shortest " electric" waves

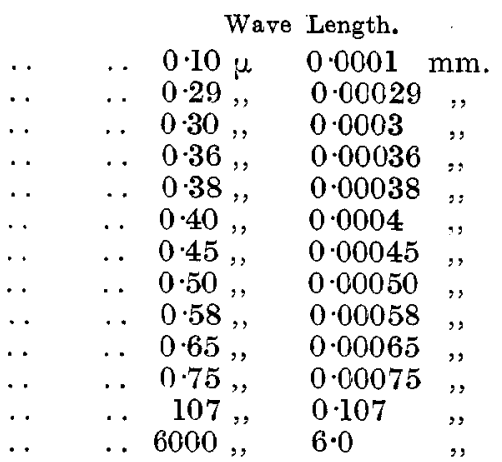

The visible spectrum represents a small interval of wave-length in comparison with the range of known radiations, but in the prismatic spectrum its importance is magnified, as the infra-red rays are "bunched " together when a beam of radiation is dispersed. In determining the distribution of energy in the spectrum, it is important to take this effect into account.

Especially in sunlight is the visible spectrum important. The point of maximum energy is at about $46 \mu$. The eyes in normal use should never receive the direct rays of the sun, but only scattered or reflected light. Blue light scattered from the sky has negligible infra-red energy, and the intensity becomes greater towards the blue end of the spectrum, but that reflected from haze, from the ground, from foliage, or even from water, may contain most wave-lengths originally present in the sun's rays.

\section{1.-Effects on the Eye.}

The physiological effects of radiation are not very fully understood, and the investigation of the subject is exceedingly difficult. The available evidence is not very full, but a summary may be useful.

It is a common experience that the eyes may be temporarily affected by exposure to an unshaded arc lamp. Under such conditions, fluorescence of the crystalline lens is caused, and, with long continued exposure, intense inflammation with final opacity of the media of the eye may result.

EXPERIMENTS OF DR. E. K. MARTIN ${ }^{3}$--Absorption tests were made on the eyes of freshly killed young rabbits. It may be assumed that radiations which are not absorbed by the refracting media of the eye are incapable of harm, but if absorption takes place deleterious effects may follow.

This series of experiments deals firstly with the absorption of the ultra-violet, the method employed being to photograph the spectrum of 
the iron arc with a quartz spectrograph, by light transmitted through a section of a part of the eye. Under these circumstances the spectrum generally is found to stop short at a certain wave-length. The results obtained were as follows :-

The Cornea absorbs waves shorter than $295 \mu$ completely, and is fairly transparent to longer wave lengths.

The Crystalline lens begins to absorb at $38 \mu$, and absorbs completely at $\cdot 35 \mu$.

The Vitreous (in a layer $\frac{3 \cdot \prime \prime}{16}$ thick) has an absorption band between $\cdot 25 \mu$ and $\cdot 28 \mu$, but seems otherwise transparent.

The Crystalline lens, then, is the first to absorb, but it will not be reached by waves shorter than $295 \mu$. As the solar spectrum stops at $\cdot 29 \mu$ (about), it would appear that daylight is practically incapable of harming the Cornea.

In this connection, it may be well to remember that small absorption is difficult to detect by direct photographic methods.

A further series of experiments was concerned with the changes produced in the eyes of living animals by exposure to ultra-violet radiation from a mercury arc for varying periods.

In general, it was found that low intensities produced no permanent results. Corneal opacity resulted from radiation of great intensity, with conjunctivitis and other phenomena. Transmission of the radiation through benzol completely stops these effects, as the shorter waves are absorbed.

\section{2.-Physiological Effects of Strong Light.}

The foregoing experiments deal with the possible effect of ultra-violet radiation on the refracting media of the eye, but equally important is the consideration of the general effect of strong illumination. Distinction must first be drawn between permanent, or semi-permanent, chemical and structural changes, and harmful effects due to muscular strain, which may be produced by excessive contrast or brightness.

As is well known, the retina consists of a sheet of nervous tissue at the back of which are located the "rods and cones." These rest against the pigment cells, which play an important part in the machinery of adaptation. Fine extensions run up between the rods from these cells, which fill with the black pigment when the eye is exposed to light. This action is probably concerned in some way with the renewing of the photo sensitive material in the retina, and possibly, by absorbing light, the pigment effects the adaptation. The maximum sensitiveness of the eye is said to be a million times as great as the minimum value ${ }^{4}$.

Direct sunlight focussed on the retina is capable of completely destroy- 
ing the nervous structures, but such an extreme case is seldom met with. Excessive light may, however, become exceedingly exhausting, as is well known to travellers in tropical regions. It is established that the eyes of Southern races are more strongly pigmented than those of Northern descent, thus providing against the greater average intensity of illumination. If the light is so bright that after images persist for an appreciable time, then "glaring" effects and discomfort result. Snow blindness will be an extreme case.

Another effect of strong light is to cause a contraction of the iris, which to some extent relieves the excess of illumination on the retina; with a flickering light this effect is said to be a cause of strain ${ }^{6}$.

A variety of so-called "glare" results from muscular efforts at accommodation or focussing when the eye seeks to observe moving objects, or to concentrate for some time on a small object. With low intensity of illumination these effects may be quite as apparent, but they must be remembered when the protection of the eyes is considered. In passing, the strain of searching the vacant field of a telescope (say) for some invisible object may be remembered. This strain may be noticed at night, and is certainly entirely muscular.

It seems to be generally admitted that contrast may have a considerable effect on vision. An American ${ }^{4}$ authority states that vision is best with contrasts of about $1: 20$, and that no discomfort results with ratios up to $1: 100$. It may be remembered, however, that the sky viewed through a small window may give a contrast of $1: 10,000$. The impaired vision in such a case results evidently from the effect that the adaptation of the eye is not adjusted to the circumstances. To work with a small light while the rest of the room is darkened may lead to considerable strain; for the best vision a fairly even illumination of the retina is seemingly of importance.

\section{Acuity of Vision.}

In this connection it may be noticed that the eye is not achromatic. A very vivid illustration of this may often be observed in a theatre, where curious stereoscopic effects are given to objects at the same distance from the eye, but illuminated by lights of differing colour. In ordinary vision no chromatic faults are generally observed, as the apparent luminosity of the spectrum is very much greater in the yellow region than in the remainder, and the focussing is done for this point of maximum luminosity. The slight lateral spreading of the badly focussed images produced by other wave-lengths is not usually noticed, but it is of importance when the very finest vision is required. Here the provision of a filter, to reduce the intensity of the violet and red ends of the visible spectrum, considerably enhances visual acuity, as has been definitely 
shown by Luckiesh in his recent book on colour. He set up a special test object, and took "acuity values" with time of exposure of the eyes, alternating with green and colourless glasses every three minutes. The result of the observations is shown in the diagram.

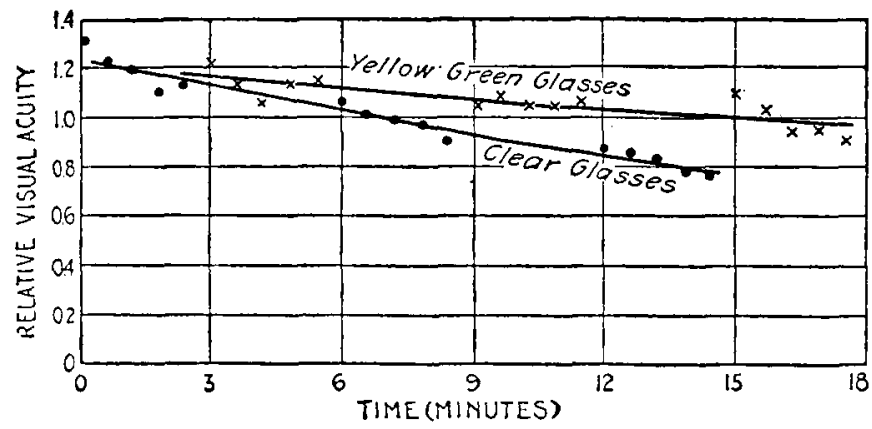

Fig. 3.

He states that the yellow-green glasses gave perceptible relief. Doubtless the improvement of vision is in some measure due to the reduction of light intensity, but also, probably, to the more nearly monochromatic nature of the light.

\section{3.-Effects of Infra-Red Rays.}

It has long been known that workers with blast furnaces, glass workers, and others, may develop cataracts in their eyes through continued exposure to heat radiations. This subject has been investigated by Sir W. Crookes. He has established that no "X" rays are emitted by molten glass, and that the radiation is chiefly confined to the longer wave-lengths.

Water is one of the most strongly absorbent substances for the infra-red. Thus it is practically certain that the refracting media of the eye would absorb infra-red radiation beyond about 1/l almost completely. The precise action of the radiations in causing opacity seems uncertain; it may be that the simple rise of temperature consequent on absorption produces the results observed. In any case, it seems clear that efficient protection from such dangers is highly important.

\section{Summary and Criticism.}

It has been conclusively shown that intense ultra-violet light is absorbed by the refracting media of the eye, and that it is then capable of producing physiological action. No absorption was detected for the visible region 
of the spectrum, but it has not been proved to be entirely absent. Sir W. Crookes, and others, conclude that physiological actions follow the absorption of infra-red radiations, resulting in cataracts.

The effects of ordinary strong illumination are retinal and muscular Contraction of the iris, and flowing of the retinal pigment, follow exposure to light. No information seems to be available as regards any variation of these effects with the colour of the stimulating light. Dr. Kerr ${ }^{6}$ states that except in cases of flicker this muscular contraction of the iris may probably be neglected as a cause of strain.

It seems that considerably more information is needed on these points. With regard to the contraction, it may be that the effect is due ${ }^{15}$ partly to the stimulation of the nervous structures surrounding the iris by the absorption of light; such a mechanism would be extremely delicate, and here, again, information is needed as to the action of the various wave-lengths in producing the phenomenon. Certainly the adaptation thus produced is small compared with retinal adaptation, but it is not clear that the strain produced in these structures by excess of light is negligible.

Filters to absorb ultra-violet radiations are by no means a panacea for relieving eye-strain and glare. Again, it will not be contended that a bright blue sky is incapable of producing glare, although the amount of infra-red energy is negligible. The first importance of a filter will be to reduce the actual luminosity of the retinal image where glare is in evidence. Absorption of the ultra-violet and infra-red will be desirable precautions in ordinary circumstances, but of the highest importance under special industrial conditions.

\section{Vision Through Telescopic Systems.}

Very definite cases of eye strain arise through the use of telescopes, especially when their use is constant, for signalling or other purposes.

Suppose that the telescope is directed towards the brightest extended area which will commonly be met with, i.e., the sky; also that the apparent brightness is I, then by a well-known theorem if

$\mu=$ index of refraction of the vitreous humour,

$p^{\prime}=$ radius of the pencil of light as it enters the eye after passing through the instrument,

$v=$ distance of the unit plane of eye from the retina,

the brightness of the retinal image will be given by ${ }^{7}$

$$
\mathrm{B}=\frac{\mu^{2} \mathrm{I} \pi p^{\prime 2}}{v^{2}}
$$


If the eye looks towards the sky without a telescope, and $p$ is the radius of the whole pupil, then the brightness $B^{\prime}$ of the retinal image will be

$$
\mathrm{B}^{\prime}=\frac{\mu^{2} \mathrm{I} \pi p^{2}}{v^{2}}
$$

When the eye views the sky directly in the average way, let the illuminated area on the retina be $A^{\prime}$; when it looks through the telescope, let the corresponding area be $A$; then the ratio of the total energy passing through the crystalline lens when using the telescope, to that when not using it, will be

$$
\frac{\mathrm{A} \cdot \mathrm{B}}{\mathrm{A}^{\prime} \cdot \mathrm{B}^{\prime}}=\frac{\mathrm{A} \cdot p^{\prime 2}}{\mathrm{~A}^{\prime} p^{2}}
$$

Since in the first case, with the telescope, an area $\pi p^{\prime 2}$ of the unit plane of the lens is concerned, and an area $\pi p^{2}$ in the second case, the ratio of the energy passing through unit cross sectional area of the lens in the two cases will be simply $\frac{A}{A^{\prime}}$

With a telescope having a small field, a small patch on the retina will be illuminated, and the energy passing through the lens will be a small fraction of that received by an ordinary eye looking at the sky. Of course, if the telescope were turned towards any brighter source, such as the sun, the energy received by the lens would become correspondingly great.

In a prism binocular, the light may have to pass through a thickness of about $8 \mathrm{~cm}$. of glass. The absorption of such a system was tested with an iron arc and quartz spectrograph, when the spectrum was found to stop short at a wave-length $34 \mu$. This points to an absorption of more than half of the supposedly harmful radiations in the ultra-violet.

Also, the theory shows that the brightness of illumination on the retina will generally be reduced when using the telescope.

It follows that the strain of using telescopic systems will seldom be due to any abnormally great intensity of light energy, although such cases arise when observing objects near the sun.

One or two possible causes of strain suggest themselves from the facts already reviewed.

(1) Contrast.-The illumination of the retina may be reduced to a small central patch surrounded by a darkened area. According to the general opinion, this is by no means the best condition for comfortable vision. Glare and strain may result from an illumination too intense for the unadapted eye.

(2) BAD Definition.-If this were present, the muscular system of the eye will be constantly seeking to focus by altering its 
accommodation-an impossible task. For the best results no higher magnification should be used than is necessary, as the definition is generally not so good.

(3) VIBRation of THE IMAGE.-Any unsteadiness in the support of the instrument will lead to greater muscular eye strain through the motion of the telescope, and consequent shifting of the image.

The intensity of illumination of the field may be reduced by providing a suitable filter. This should stop ultra-violet well, and also a considerable proportion of the visible energy. If the telescope be ssed to view objects near the sun, some infra-red energy will be received, due to reflection from the haze. It would thus be a precaution to use a filter to absorb as much infra-red as possible. The use of a coloured filter to render the radiation more monochromatic will improve observation. Haze and excessive blue light may be avoided by suitably coloured filters, green, yellow and red being variously employed.

It will further be an advantage that the instrument should possess a large field of view, thus obtaining a broad retinal illumination. The provision of a stop to cut down the field to that part illuminated by full pencils will be, in this connection, a doubtful advantage.

\section{Methods and Apparatus Employed for Testing Light Filters.}

The present paper cannot deal fully with methods of spectrophotometry in general, but a short descripiton of the apparatus and methods used to obtain the results about to be given will perhaps be of interest.

\section{(1) Ultra-Violet Region.}

Visual methods are, of course, impossible, and recourse must be had to photographic, photo-electric, or other methods. For the present work the combined photographic and photometric apparatus, made by Miessrs. Hilger, Ltd.," was employed for a series of experiments, and a full description of the method will be found in their catalogues. The diagram shows the arrangement.

In effect, the object is to illuminate half the slit of a quartz spectrograph by radiations passing through a test specimen, and the other half by full radiation from the same source. In the path of each beam is a rotating sector (one of variable angle), by means of which the ratio of the exposures may be varied. In practice, the sector aperture for the unabsorbed beam is reduced. 
When no specimen is present, and the aperture of both sectors is $90^{\circ}$ a photograph taken of the spectrum should show the two spectra from each hal: of the slit side by side, and of exactly equal density. When

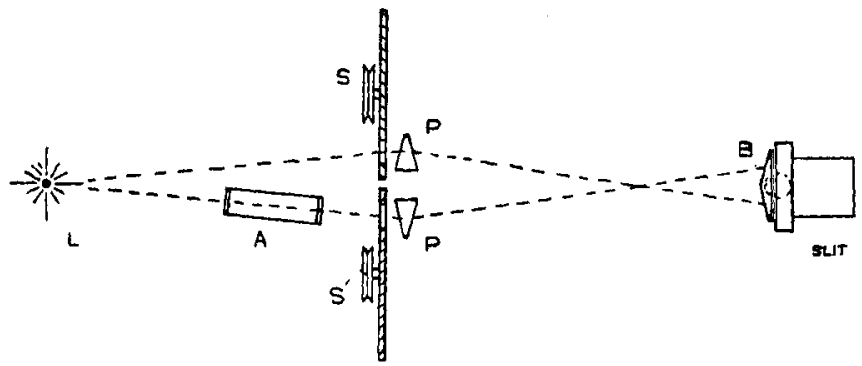

FiG. 4.

a specimen is in the path of one beam, and the exposure of the other is reduced in some known ratio, the adjacent spectra may give equal density on the plate at a certain measurable wave-length.

Quoting the catalogues, "Let the tractions of whole revolucions during which the variable and fixed aperture sectors allow light to pass be respec tively $t$ and $t^{1}$ and let the intensities of light of wave-length $\lambda$, reaching the slit by the upper and lower beams in the figure, be respectively I and $I_{1}$. Then, if at wave-length $\lambda$ the density is exactly the same in both spectra, we have

$$
\mathrm{I}_{\mathrm{I}}=f\left(t_{1}, t\right)
$$

According to Schwarzschild, the relation for uninterrupted exposures is of the form,

$$
I_{1}=\left(\frac{t^{n}}{t}\right)^{n}
$$

where $n$ is a constant depending on the particular kind of photographic plate employed."

Messrs. Hilger supply with the apparatus a glass plate calibrated for absorption by another method based on the uniform transmission throughout the spectrum of a quartz plate, heavily silvered, and from which a certain area of silver has been removed by scratching. This glass plate is used to determine the constant $n$ for the plates employed, the formula of Schwarzschild being assumed to hold.

In a recent number of the Physical Review, however, Professor Howe ${ }^{10}$ describes experiments which he interprets as indicating that reliable results for absorption can be obtained direct from the ratio of the sector openings, but even if this be correct it is difficult to see where Messrs. Hilgers method of getting the absorption of their standard glass plate 
fails. Uncil we have more exact information on the subject it seems that results obtained must be used with caution. Considered relatively, however, they are extremely interesting as showing the behaviour of the variously coloured specimens, and the effects of their thickness.

Up to the present time it has been found necessary to employ a con densed discharge between uranium electrodes, or some such arrangement, for the source of light. A new departure was to use the "Pointolite" Tungsten arc-lamp of the Ediswan Co. This is quite satisfactory if over-run, as the nitrogen bands, which are somewhat troublesome and prominent, then become merged in continuous spectrum. This, of course, shortens the life of the lamp. For testing the absorption of glasses the spectrum given is sufficient, but it would scarcely be practical to use the lamp, even in a quartz bulb, for such work as this between $2 \mu$ and $3 \mu$.

For the purpose of this work, Professor Howe's deductions have been assumed to be correct, but the results can be modified if alteration is found to be necessary. Comparatively few results have been at present obtained with this apparatus, but it is hoped that their interest will justify their inclusion in the paper.

\section{Limit of Transmission.}

The coefficient of absorption of glasses becomes very high in the ultraviolet, and beyond a certain region for each specimen no transmission can, in general, be detected under standard circumstances. The thickness of the glass, intensity of the source, and the exposure, all affect the apparent limit of transmission, as does the construction of the spectrograph employed in the experiment. Consistent results under similar circumstances can, however, be obtained, and considerable information may be deduced regarding the transmission.

For the present work a small quartz spectrograph was employed; light from an iron arc was focussed on the slit by a quartz lens, and a photograph taken with each specimen in turn in front of the slit; five seconds exposure was given. From the resulting photographs the limits of transmission were found by means of a map of the iron spectrum. Comparing the results thus obtained with those given by the photometer, it will be seen that the "limit" corresponds to a transmission of something less than 1 per cent., or thereabouts, of the initial radiation.

\section{(2) Apparatus for the Visible Spectrum.}

I have been enabled to use this apparatus through the courtesy of Sir William Abney, who has already described it fully"

It consists of an apparatus to form a spectrum; in the plane of this 
spectrum is placed a narrow slit, which thus emits fairly monochromatic radiations. A three-pole arc lamp (giving a very bright and steady light) is used as a source. The further arrangement is shown in the diagram.

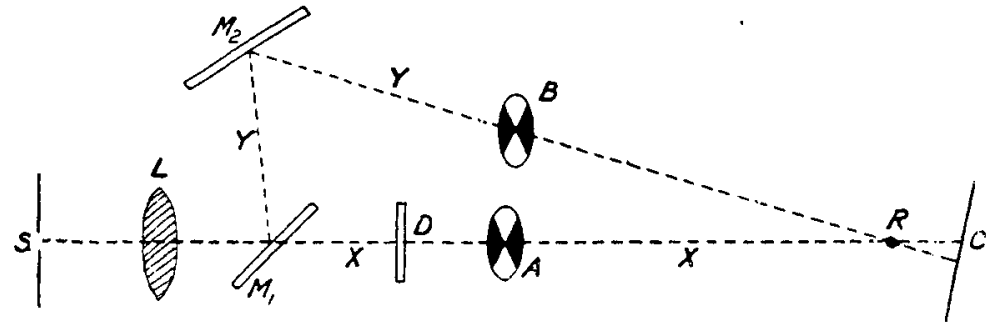

FIG. 5.

$\mathrm{S}$ is the slit moving in the spectrum, $\mathrm{L}$ the lens, which is so arranged as to throw the image of the first prism face in the spectrum apparatus on the screen $C$. A glass plate or bundle of plates, $M_{1}$, reflects a part of the beam to the second mirror $M_{2}$, whence it comes back to the screen $C$. Sectors can be inserted in one or both of the beams. A rod $R$ is placed so as to give two shadows, touching one another at $\mathrm{C}$. We thus have one-half of the screen illuminatd by one beam, and half by the other. The test specimen is placed in the path of the main beam, and the brightness of the shadows again equalised by adjustment of the sectors. A screen of metal coated with the white powder from burning magnesium is used throughout; the rest of the room must be kept in absolute darkness. The measurement may be made for light of any spectral colour by moving the slide on which the slit is mounted. A scale giving wavelengths is carried by the slide.

Extremely good and consistent results can be obtained by the use of this apparatus, which is naturally more accurate than spectrophotometers of the Nicol Prism type, where the results depend on the squares of the tangents of angles.

The fact that the apparent luminosity of a screen, illuminated by light interrupted by a rotatory sector, is proportional to the angular aperture of the sector has been well established by experiment. Consequently it is only necessary to equalise the two shadows before putting the specimen in place and after, when the transmission follows simply from the ratios of the openings.

\section{(3) Apparatus Used for the Infra-Red.}

I am indebted to Professor Callendar for permission to use this apparatus, which was specially designed by him some eight years ago 
for infra-red work. It is essentially a mirror spectrometer with a rocksalt prism. The dispersed image of the slit is focussed in the plane of another slit immediately behind which is placed an exceedingly delicate

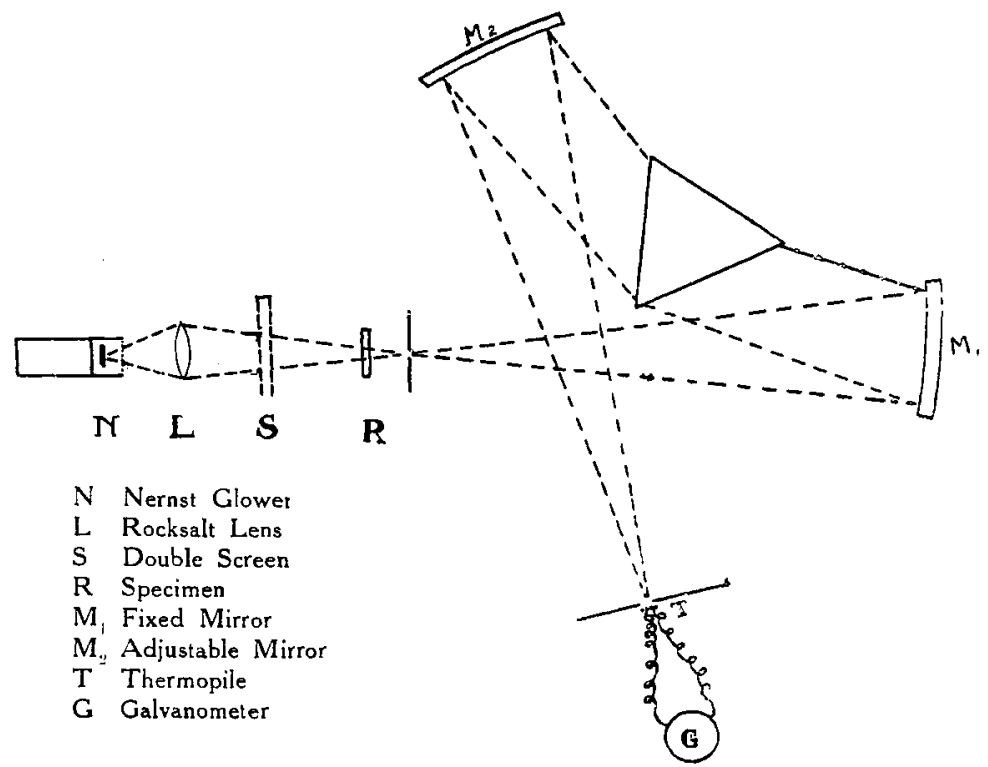

FIG. 6

thermopile. Means are provided for rotating the second mirror. This action moves the spectrum across the plane of the second slit, and in this manner exceedingly small portions of the visible or infra-red spectrum are allowed to fall on the face of the thermopile. The whole apparatus is enclosed in a heavily lagged box to prevent temperature disturbances.

In infra red work it is, if possible, desirable to use a grating in order to obtain wave-lengths accurately, but in the present circumstances this was not possible. Accordingly, the following means were adopted for calibration :-

(1) The thermopile was displaced from behind the slit, and a reflecting prism was arranged so that the light passing through the slit could be viewed through a telescope.

(2) The rocksalt prism was rotated, and the mirror adjusted till the Lithium line $(\cdot 6104)$ was at minimum deviation in the centre of the slit. Having given this arrangement, and knowing the angle of the prism, the angular distribution of the various wavelengths can be calculated from the results given by Rubens ${ }^{2}$. 
(3) The lines ( 5890$)$ Sodium, (-6104) Lithium, (-6708) Lithium, were brought in turn to the centre of the field (with a very narrow slit), and the corresponding readings taken on the scale of the tangent action by means of which the mirror is rotated. The angular motion of the mirror for a given movement on this scale can easily be found.

(4) The thermopile is replaced and the slit widened. A strong Bunsen burner flame is now placed in front of the first slit. This gives an emission band at $4 \cdot 4 \alpha^{13}$, due to the heated carbon dioxide. The position of this band is well authenticated. It is now found on the tangent scale by rotating the mirror and observing the deflection of the galvanometer. Another point which may be found is the water absorption band very close to $3 \cdot 0 \mu$. This band has been located by several experimenters ${ }^{13}$ at slightly differing places. For purposes of the present work the absorption of a thin plate of selenite, which contains water of crystallisation and exhibits the band very well, was investigated. The position of this was found as accurately as possible and assumed to lie exactly at $3 \cdot 0 \mu$.

(5) The angular motions for these wave-lengths, $3.0 \mu$ and $4.4 \mu$, were calculated from readings in (3) for visible lines, and from Rubens' results; the readings actually found being then used to apply a small correction, interpolating for the correction at intermediate wave-lengths.

In this manner, wave-lengths may be located with considerable accuracy on the assumption of the position of the water-band in the selenite plate. The results can be corrected if at any time this is shown to be wrong.

Having thus a means for measuring the intensity of radiation in different parts of the spectrum, the absorption of substances can be obtained provided that a steady source of radiation is available. It was desired to investigate the region from $7 \mu$ to $5 \mu$, and for this purpose a Nernst glower gives a fairly satisfactory emission, but is liable to be unsteady in ordinary circumstances. After many trials, the arrangement finally adopted was to enclose the lamp in a chimney of mica, with a thin quartz window ; the glower is thus kept quite free from draughts. It is important also to ensure that the current taken shall be constant. For these experiments a spare set of accumulators which give a very constant E.M.F. was used. These precautions are extremely important. The image of the filament was focussed on the slit by means of a rocksalt lens, the whole 
arrangement being made very steady. The focussing was varied till the deflection at the longer wave-length was as great as possible, which position, of course, was entirely different from the focus for the visible rays. This helps to keep the galvanometer deflections a little more uniform throughout the spectrum. A further trouble was met in parasitic E.M.F.'s in the thermopile circuit, which necessitated taking the zero for every two readings. For a long time the zero was taken by lowering a screen immediately in front of the thermopile, but this was found to vary slightly in temperature from the pile itself, and consequently a false zero was indicated. This, unfortunately, entailed the putting on one side of a great deal of work which had already been done. Finally, however, by the careful observation of these several precautions, consistent results could be obtained. For the purpose of this work it is not sufficient merely to locate the position of the absorption bands in the spectrum, which has been the object of most work done in the infra-red ; the exact numerical value of the proportion of energy for various wavelengths which is transmitted must be found.

The secondary corrections for error due to non-parallelism of the beam passing through the test specimen, also for the small finite range of the spectrum allowed to fall on the thermopile have not been judged of sufficient importance for special notice in these experiments on absorption. Experimental details diminished errors due to such effects as far as possible.

\section{General Remarks on the Methods and Results.}

For all purposes the nature and position of the absorbing specimen is of importance. It must have good plane surfaces well polished. Bad surfaces can easily introduce a 20 per cent. error.

In the first two methods, variation of the source is allowed for by the simultaneous action of two beams, but extreme steadiness is of great importance in infra-red work.

The limits of accuracy of the measurements in the ultra-violet cannot at present be indicated, as sufficient experience of the method has not been gained. In the visible spectrum, results should be accurate to 1 in 100 at least. In the infra-red, where absolute consistency is even more difficult, results being obtained with different calibrations of the apparatus, and fresh adjustments of the radiator, lens and specimen, a general agreement to 2 or 3 in 100 is shown. The extreme results in the infra-red (wave-lengths 0.73 and $4.6 \mu$ ) are liable to greater uncertainty, as here the actual galvanometer deflections do not exceed 3 or $4 \mathrm{~mm}$. for the unabsorbed radiation. 


\section{Absorption of Radiation.}

It can be shown from theoretical considerations that an electromagnetic wave, propagated in a material substance, will in general part with some of its energy to the electrons present, and this conclusion is, of course, confirmed from experience. The energy may re-appear as a re-emission of light in resonance radiation, fluorescence, or phosphorescence; it may become apparent in chemical action, in a rise of temperature, or in other ways.

The theoretical law states that if $I_{0}$ is the initial value of the energy in a light wave, the energy after passing through a thickness $t$ of the medium, will be

$$
\mathrm{I}_{\mathrm{I}}=\mathrm{I}_{\mathrm{o}} e^{-\mathrm{a} t},
$$

$a$ is known as the coefficient of absorption.

This law holds for all homogenous transparent substances such as the glasses to be dealt with later; no attempt must be made to apply it to any such cases as stained light filters of celluloid. Stated in a simple form, the law shows that if a first thickness $t$ of a material transmits a fraction $a$ of the incident radiation, then the second thickness $t$ will transmit the same fraction of the radiation incident upon it; $a^{2}$ will be the fraction transmitted by the two.

Theoretical considerations, again verified by experiment, give the intensity of the reflected light for normal incidence on a plane surface as

$$
\left(\frac{n-1}{n+1}\right)^{2}
$$

of the incident light where $n$ is the refractive index. This corresponds to a transmission factor

$$
=\left\{1-\left(\frac{n-1}{n+1}\right)^{2}\right\}=(1-\beta), \text { say. }
$$

Then if $I_{0}$ is the incident radiation

Amount transmitted by 1 st face $=I_{\circ}(1-\beta)$

$$
\begin{array}{ll}
\text { thickness of material } & =I_{0}(1-\beta) e^{-a t} \\
2 n d \text { face } & =I_{0}(1-\beta)^{2} e^{-a t}
\end{array}
$$

There will also be multiple reflections giving rise to further amounts emerging in the first direction with the transmitted beam,

$$
\begin{aligned}
& I_{0}(1-\beta)^{2} \beta^{2} e^{-3 a t}, \\
& I_{0}(1-\beta)^{2} \beta^{4} e^{-5 a t}, \\
& + \text { etc. }
\end{aligned}
$$


The total amount transmitted

$$
\begin{aligned}
& =\mathrm{I}_{0}(1-\beta)^{2} e^{-u t}+\mathrm{I}_{0}(1-\beta)^{2} \beta^{2} e^{-3 u t}+\mathrm{I}_{0}(1-\beta)^{2} \beta 4 e^{5 a t},+ \text { etc. } \\
& =\mathrm{I}_{0}(1-\beta)^{2} e^{-u t}\left\{1+\beta^{2} e^{-2 u t}+\beta^{4} e^{-4 a t},+ \text { etc. }\right\} \\
& =\frac{I_{0}(1-\beta)^{2} e^{-a t}}{\left(1-\beta^{2} e^{-g_{a} t}\right)}
\end{aligned}
$$

The values of the refractive index in the visible and infra-red for various glasses have been determined by Rubens ${ }^{8}$. He shows that for most glasses the refractive index falls slowly with increasing wave-length. Hence $\beta$, which is about $\frac{1}{25}$ for ordinary glass, will steadily diminish. The term $\beta^{2} e^{-2 a t}$ may thus be neglected for most purposes, and the formula becomes

$$
I_{\mathrm{x}}=\mathrm{I}_{\mathrm{o}}(1-\beta)^{2} e^{-a t}
$$

The formula may safely be used for glass till the region of quasi-metallic reflection is reached, when the substance will appear to be quite opaque.

Having measured the fraction $\frac{I_{1}}{I_{0}}$ for a plate of thickness $t$, we can make an allowance for the reflection by assuming a value for $\beta$. Thus, if the refractive index be 1.5 ,

$$
\beta=\left(\frac{5}{2 \cdot 5}\right)^{2}=\frac{1}{25}
$$

We shâll have

$$
\log \frac{\mathrm{I}_{1}}{\bar{I}_{\mathrm{o}}}=\log (1-\beta)^{2}-a t
$$

We can calculate $a$ and thence find the transmission for any other thickness of the material. If $\beta=\frac{1}{25}$, the practical formula will be

$$
\log _{\mathrm{x} 0} \frac{\mathrm{I}_{\mathrm{r}}}{\mathrm{I}_{\mathrm{o}}}=\log _{\mathrm{x} 0} 0 \cdot 9 \cdot 2+\mathrm{K} t
$$

By measuring the transmission of a plate of another thickness we can dispense with an assumed value for $\beta$; we shall get the value of

then

$$
I^{\prime} \text { (say) }=I_{0}(1-\beta)^{2} e^{-a t^{\prime}}
$$

$$
\frac{\mathrm{I}_{\mathrm{r}}}{\mathrm{I}^{\prime}}=e^{a\left(t^{\prime}-t\right)} \text {, whence } a \text { may be found. }
$$

For ordinary purposes we may work to the logarithm base 10 for convenience, the coefficient ${ }^{16}$ in this case being known as the "extinctioncoefficient." This short account of the theory will enable the results to be given to be transformed for other thicknesses. 
In many scientific papers it is usual to calculate the value of the extinction-coefficient, and to give tables of this quantity. For the purposes of this work, however, it has been judged more useful to give the actual percentage transmission of definite specimens, with their thicknesses. Results can be transformed if necessary, but the curves will give a better idea of the actual performances of light filters than " extinction-coefficient" diagrams.

In order to summarise the results, the areas under the percentage curves for a given range of wave-length, expressed as fractions of the whole rectangle for that range, will give a measure of the general performance of a filter. This has been done for most of the specimens in the visible and infrarred regions. See table on page 91.

\section{Composition of the Filters Tested.}

(1) Neutral Glasses.-These are best produced by the use of nickel, manganese, iron, cobalt, and other oxides in amounts varying with special circumstances. The exact origin of the filters tested is unfortunately not known, but very similar properties are shown by glasses from three different sources.

(2) "Crookes" Spectacle Glass.-This is made by Messrs. Chance, and its exact composition has not been published. Its approximate composition may, however, be inferred from the paper in the "Phil. Trans." already referred to.

Glass 202 contains ferric iron and cobalt.

Glass 246 contains ferrous iron.

(3) FieUzal Glasses.-These have green tints probably due to chromium. They show the increased transmission due to $\mathrm{Cr}$. at the red end of the spectrum noticed by Zsigmondy ${ }^{14}$.

(4) Hallauer Glasses.-These are of German origin, supposed to be a combination of a green with a smoke tint.

(6) Signal Green Glasses.-These are soda lime glasses with varying amounts of cupric oxide.

(7) Yellow and Red Glass Series.-These colours may be produced by the addition of varying amounts of nickel with other substances, also by the use of sulphur or selenium.

(8) The Celluloid Specimens were strongly coloured by dye compositions. 


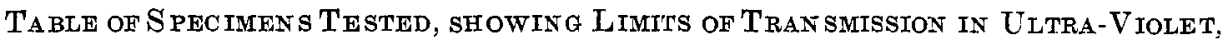
and Relative Energy Transmissions in the Visible and InjRa-Red.

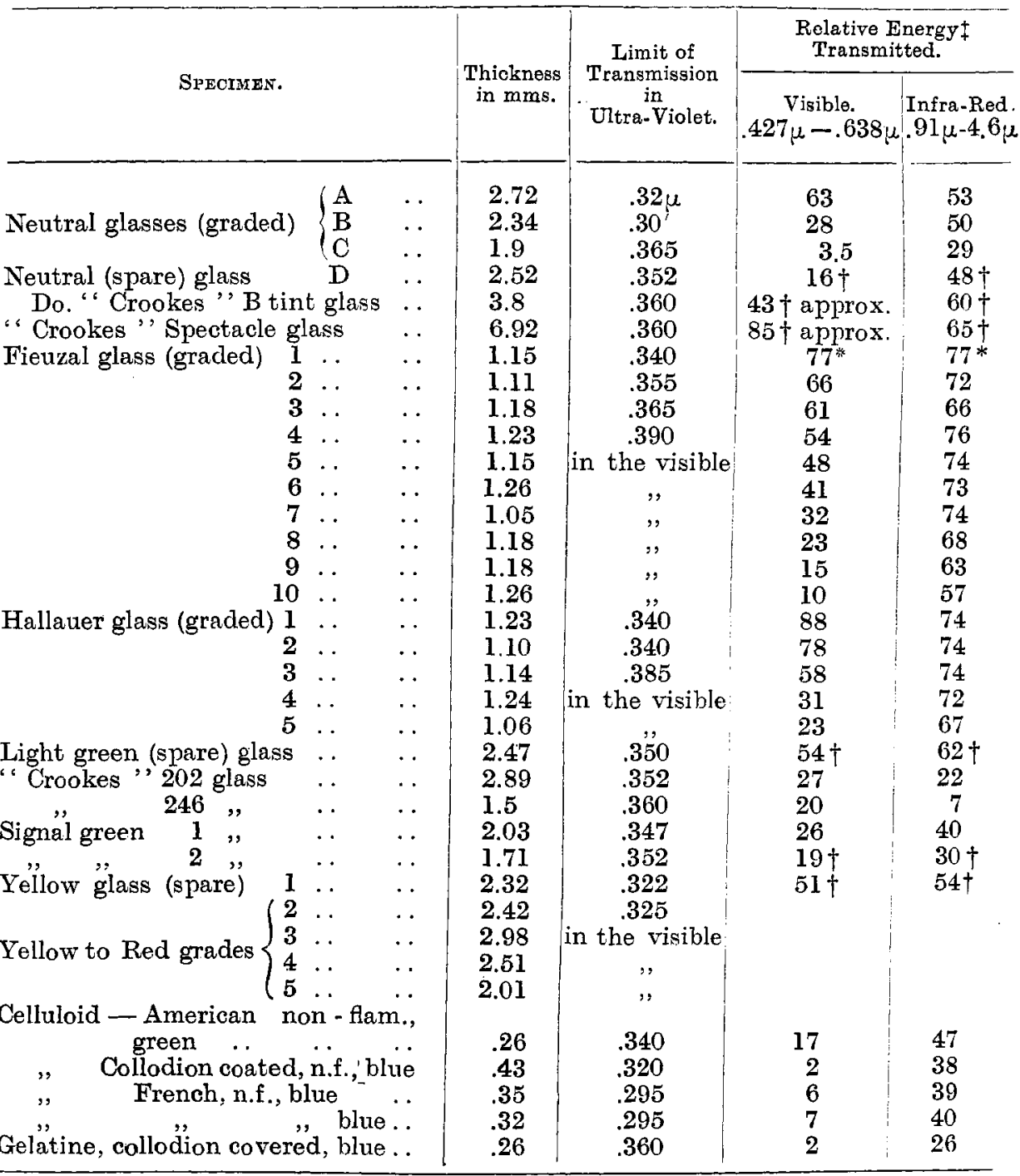

REFERENCES. $-\dagger$ Value calculated for a thickness $=2 \mathrm{~mm}$.

* Ranges of wave length for Fieuzal and Hallauer glasses were $.427 \mu-.692 \mu$ and $.73 \mu$ to $4.6 \mu$ for visible and infra-red

$\ddagger$ The energy transmitted by a filter depends on the source of radiation. 
Ultra-Violet Transmission. Hilger Spectrometer Results. Table showing Wave-Lengths for given Percentage Transmissions.

WAVE-Iangth IN TuRMS OF $\mu$.

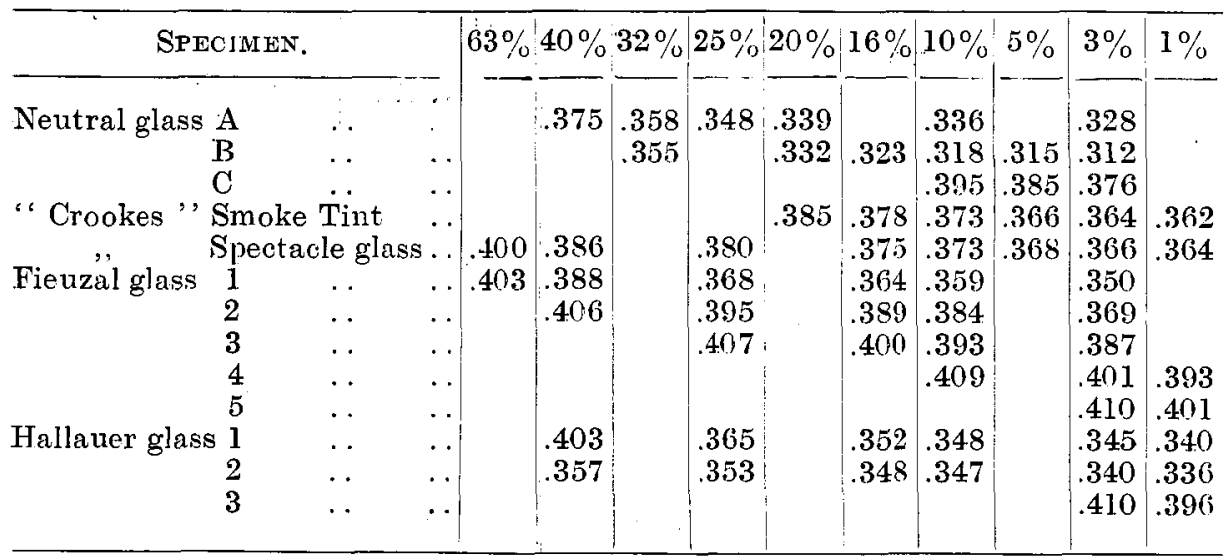

Vistrima Spectrum. Percentage Tran smission and Wave-Langth.

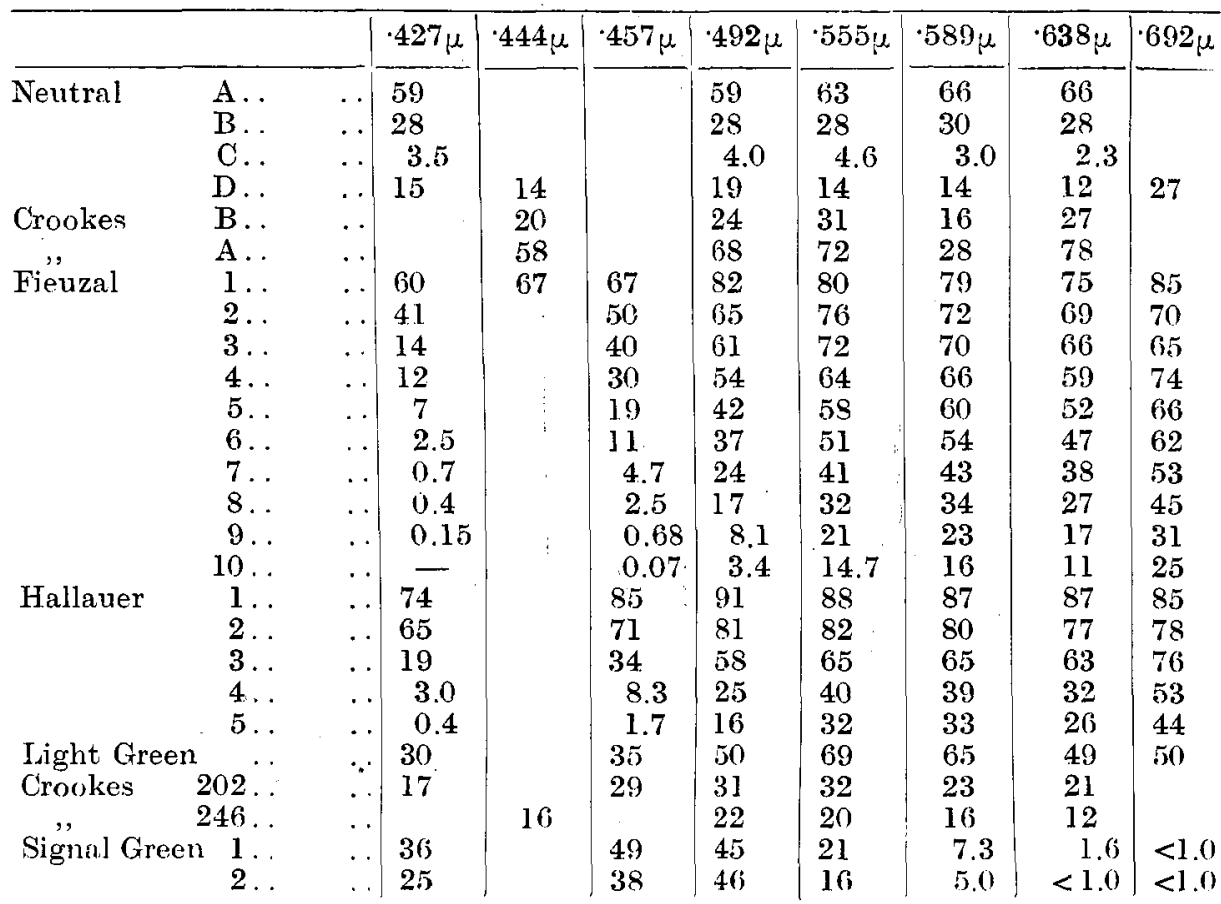


Visible Spectrum. Percentage Transmission and Wave-Length-contd.

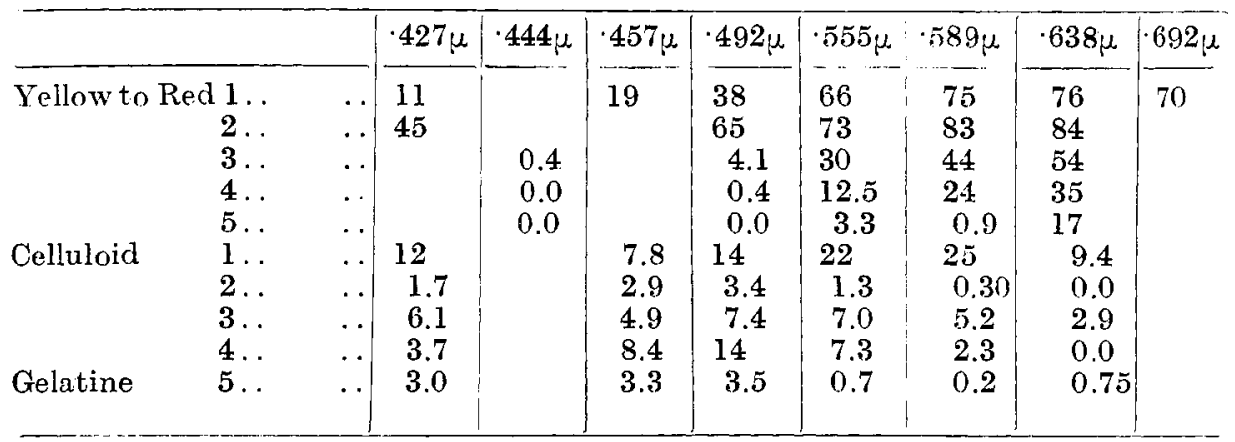

Infra-Red Spectrum. Percentage Transmission and Wave-Length.

\begin{tabular}{|c|c|c|c|c|c|c|c|c|c|c|c|c|c|c|}
\hline \multicolumn{5}{|c|}{ Wave-length $(\mu)$} & .90 & 1.43 & 2.05 & 2.47 & 3.0 & 3.56 & 4.18 & 4.54 & & \\
\hline \multicolumn{3}{|c|}{$\begin{array}{l}\text { Neutral A } \\
\text { B } \\
\text { C } \\
\text { D } \\
\text { " Crookes B ," } \\
\text { "Crookes A ", } \\
\text { Light Green } \\
\text { Signal Green 2 }\end{array}$} & $\begin{array}{l}\cdots \\
\cdots \\
\cdots \\
\cdots \\
\cdots \\
\cdots\end{array}$ & $\begin{array}{l}\cdots \\
\cdots \\
\cdots \\
\cdots \\
\cdots \\
\cdots \\
\cdots\end{array}$ & $\begin{array}{l}79 \\
66 \\
30 \\
52 \\
64 \\
60 \\
79 \\
1.2\end{array}$ & $\begin{array}{c}76 \\
70 \\
29 \\
58 \\
68 \\
72 \\
86 \\
10.5\end{array}$ & $\begin{array}{l}79 \\
66 \\
36 \\
60 \\
65 \\
76 \\
86 \\
54\end{array}$ & $\begin{array}{l}80 \\
72 \\
46 \\
67 \\
66 \\
70 \\
85 \\
67\end{array}$ & $\begin{array}{l}33 \\
34 \\
21 \\
44 \\
18 \\
7.7 \\
49 \\
43\end{array}$ & $\begin{array}{c}21 \\
26 \\
18 \\
37 \\
9 \\
2.7 \\
39 \\
32\end{array}$ & $\begin{array}{l}20 \\
30 \\
22 \\
35 \\
17 \\
12 \\
35 \\
29\end{array}$ & \begin{tabular}{|c|}
17 \\
22 \\
15 \\
9.7 \\
12 \\
12 \\
24 \\
12
\end{tabular} & & \\
\hline \multicolumn{5}{|c|}{ Wave-length $(\mu)$} & .73 & .91 & 1.28 & 1.67 & 2.65 & 3.15 & 3.55 & 3.95 & 4.3 & 4.6 \\
\hline euzal & $\begin{array}{r}1 \\
2 \\
3 \\
4 \\
5 \\
6 \\
7 \\
8 \\
9 \\
10\end{array}$ & $\begin{array}{l}\ldots \\
\ldots \\
\ldots \\
\ldots \\
\ldots \\
\ldots \\
\cdots \\
\ldots \\
\ldots\end{array}$ & $\begin{array}{l}\cdots \\
\cdots \\
\cdots \\
\cdots \\
\cdots \\
\ldots \\
\cdots \\
\cdots\end{array}$ & $\begin{array}{l}\ldots \\
\cdots \\
\cdots \\
\cdots \\
\cdots \\
\cdots \\
\cdots \\
\cdots\end{array}$ & $\begin{array}{l}88 \\
73 \\
60 \\
82 \\
73 \\
76 \\
73 \\
62 \\
55 \\
53\end{array}$ & $\begin{array}{l}82 \\
67 \\
58 \\
82 \\
78 \\
77 \\
76 \\
70 \\
64 \\
58\end{array}$ & $\begin{array}{l}82 \\
69 \\
60 \\
85 \\
82 \\
79 \\
79 \\
75 \\
68 \\
63\end{array}$ & $\begin{array}{l}79 \\
71 \\
84 \\
81 \\
78 \\
77 \\
72 \\
65 \\
59\end{array}$ & $\begin{array}{l}88 \\
81 \\
76 \\
85 \\
81 \\
78 \\
78 \\
74 \\
66 \\
62\end{array}$ & & $\begin{array}{l}70 \\
67 \\
64 \\
68 \\
68 \\
66 \\
69 \\
64 \\
58 \\
54\end{array}$ & $\begin{array}{l}71 \\
68 \\
65 \\
68 \\
69 \\
66 \\
69 \\
65 \\
59 \\
55\end{array}$ & $\begin{array}{l}63 \\
62 \\
60 \\
63 \\
67 \\
63 \\
64 \\
58 \\
58 \\
50\end{array}$ & $\begin{array}{l}42 \\
45 \\
44 \\
46 \\
45 \\
43 \\
47 \\
34 \\
47 \\
29\end{array}$ \\
\hline Hallauer & $\begin{array}{l}1 \\
2 \\
3 \\
4 \\
5\end{array}$ & $\begin{array}{l}\ldots \\
\ldots \\
\ldots \\
\ldots\end{array}$ & $\begin{array}{l}\ldots \\
\cdots \\
\cdots\end{array}$ & $\begin{array}{l}\ldots \\
\ldots \\
\ldots \\
\ldots\end{array}$ & $\begin{array}{l}75 \\
85 \\
78 \\
71 \\
62\end{array}$ & $\begin{array}{l}82 \\
83 \\
89 \\
79 \\
61\end{array}$ & $\begin{array}{l}82 \\
83 \\
89 \\
83 \\
64\end{array}$ & 84 & $\begin{array}{l}83 \\
83 \\
82 \\
78 \\
72\end{array}$ & $\begin{array}{l}76 \\
73 \\
72 \\
69 \\
68\end{array}$ & $\begin{array}{l}69 \\
68 \\
66 \\
65 \\
63\end{array}$ & $\begin{array}{l}64 \\
63 \\
63 \\
63 \\
62\end{array}$ & $\begin{array}{l}\mathbf{5 7} \\
54 \\
\mathbf{5 5} \\
\mathbf{5 8} \\
57\end{array}$ & $\begin{array}{l}49 \\
47 \\
44 \\
27 \\
47\end{array}$ \\
\hline Crowkes & 202 & $\cdots$ & & & 34 & 19 & 15 & 33 & 38 & 10 & & 8 & 5 & \\
\hline Celluloid & $\begin{array}{l}1 \\
2 \\
3 \\
4\end{array}$ & $\begin{array}{l}\ldots \\
\ldots \\
\ldots\end{array}$ & $\begin{array}{l}\ldots \\
\ldots \\
\ldots\end{array}$ & $\begin{array}{l}\ldots \\
\ldots \\
\ldots\end{array}$ & $\begin{array}{l}77 \\
69 \\
29 \\
26\end{array}$ & $\begin{array}{l}82 \\
80 \\
59 \\
61\end{array}$ & $\begin{array}{l}87 \\
79 \\
77 \\
72\end{array}$ & $\begin{array}{l}79 \\
76 \\
72 \\
70\end{array}$ & $\begin{array}{l}50 \\
34 \\
43 \\
45\end{array}$ & $\begin{array}{r}15 \\
7 \\
7 \\
9\end{array}$ & & $\begin{array}{l}23 \\
11 \\
14 \\
14\end{array}$ & $\begin{array}{l}26 \\
14 \\
15 \\
22\end{array}$ & $\begin{array}{r}25 \\
7 \\
27 \\
25\end{array}$ \\
\hline Gelatine & 5 & & & & 12 & 6 & 50 & 58 & 31 & 3 & & 4 & 5 & 8 \\
\hline
\end{tabular}


Infra-Red Spectrum. Phrcentage Transmission and Wave-Iength-contd.

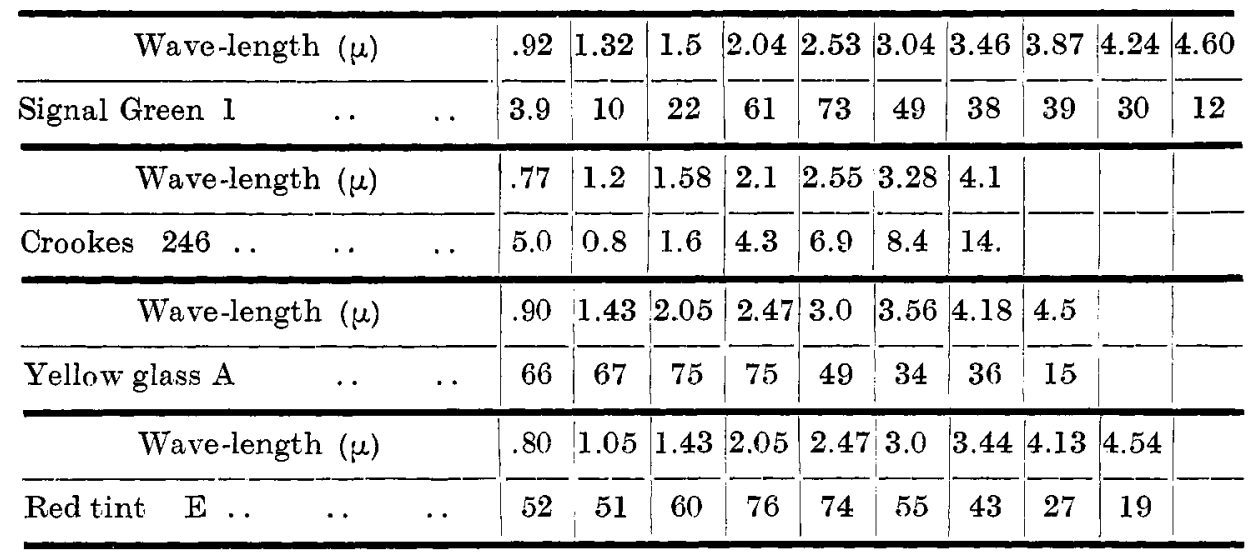

Analysis of Results. Diagrams Showing Percentage Transmission and Wave-Length.

(1) Neutral Glasses.-Note the effect of thickness on ultra-violet transmission. B transmits more than A from .30 to .35 . When only 3 or 4 per cent. of light is transmitted, iransmission stops at .36. In the visible there is little to notice. Few glasses show no variation in per-

NEUTRAL GLASSES.

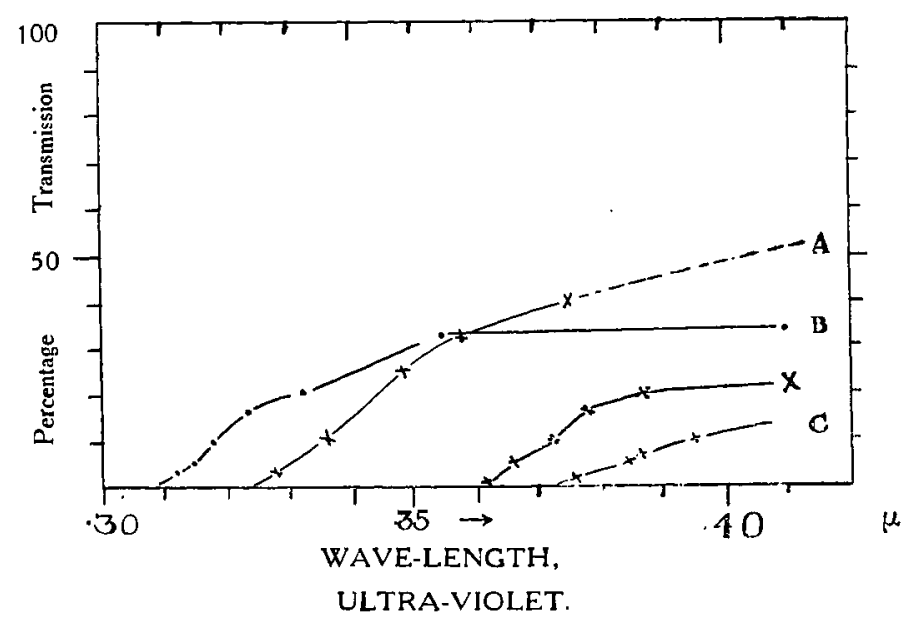


Light Filters for Eye Protection.

NEUTRAL GLASSES.

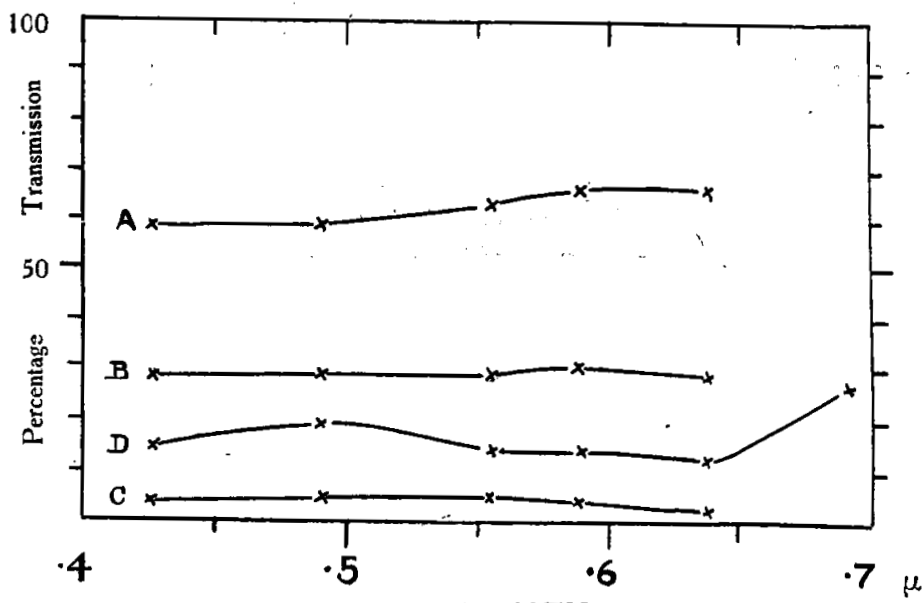

WAVE-LENGTH.

VISIBLE.

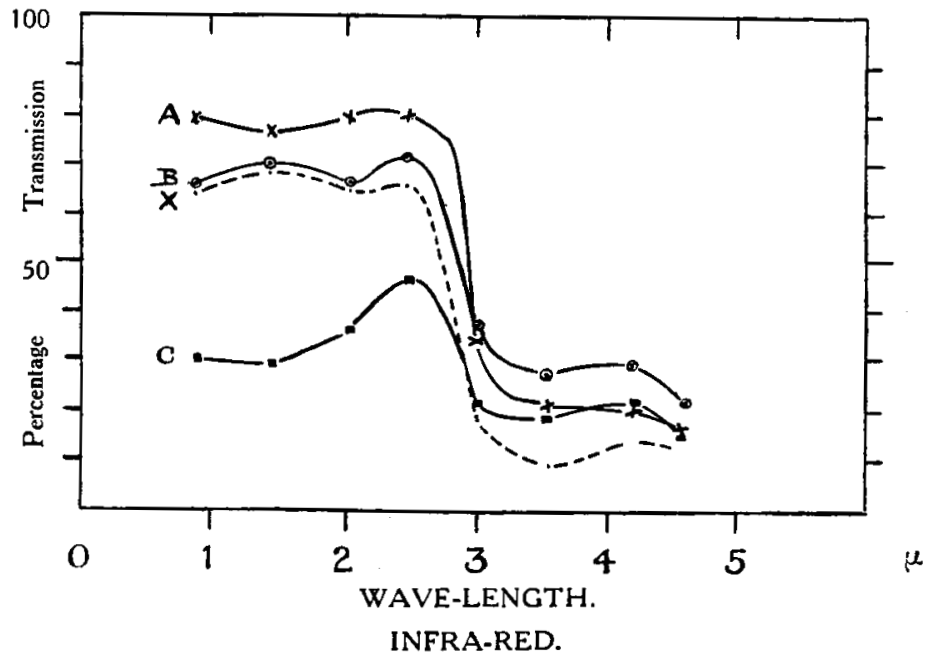

A B C, Graded Tints; D, Spare Spccimen ; X, Crookes' ' B' Tint.

centage transmission. "Crookes" B tint is not shown for the visible region, as in common with the "Crookes" ordinary (white) glass it has an absorption band, due to didymium, the exact form of which has not been invesiigated. 
In the infra-red the effect of the colouring substance falls off towards the longer wave-lengths. Note the transmission of $C$, which rises to equality with $\mathrm{A}$ at about $4 i$. This effect is very general throughout the glasses tested. $\mathrm{X}$ absorbs more at long wave-lengths owing to the greater thickness of the specimen.

\section{CROOKES' GLASS}

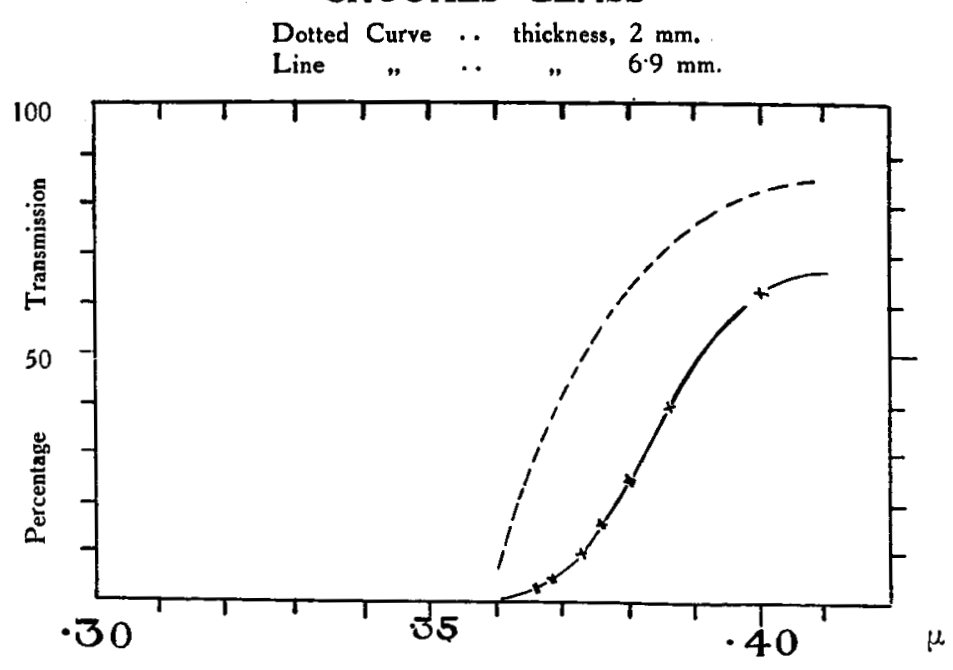

WAVE-LENGTH.

ULTRA-VIOLET.

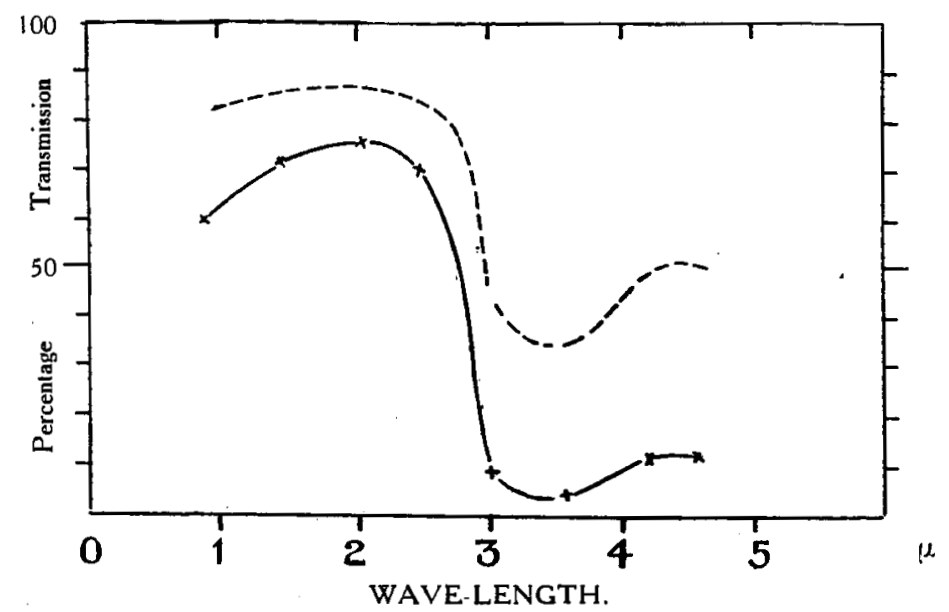

INFRA-RED. 
(2) "CROokes" Glass (A Tint).-At a thickness of $6.92 \mathrm{~mm}$. this glass transmits well in the infra-red, but absorbs heavily in the ultraviolet. There is no measurable transmission after .36 $\mu$. The results have been reduced by calculation to a value for $2 \mathrm{~mm}$., and the resulting curve is shown for the ultra-violet and infra-red regions. The following table shows the effect of change of thickness.

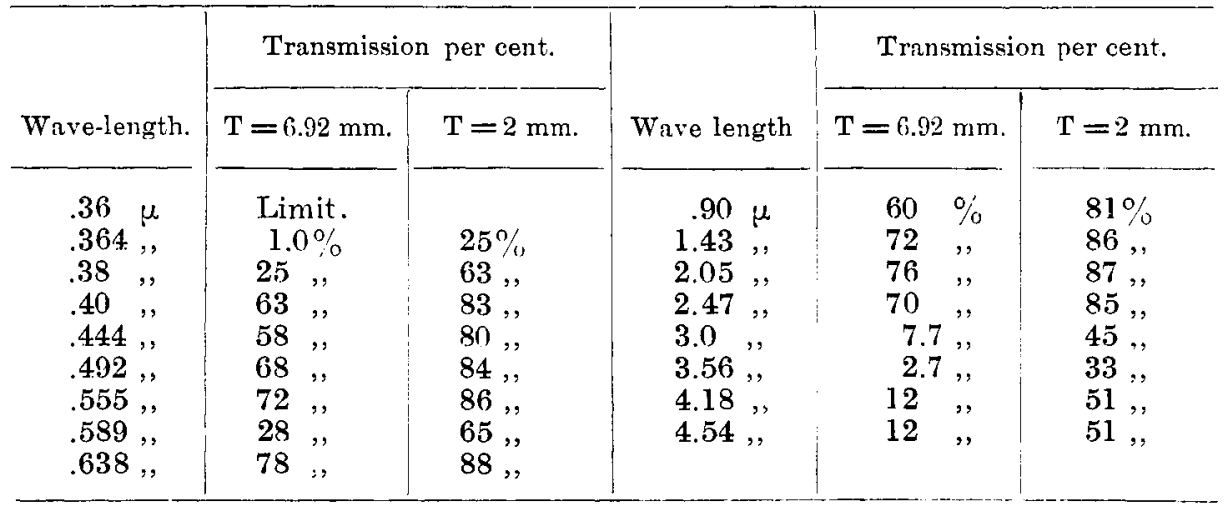

FieUzal GLASSES.-The absorption of the ultra-violet rapidly increases with depth of colour. When the visible energy is halved, the transmission FIEUZAL GLASSES.

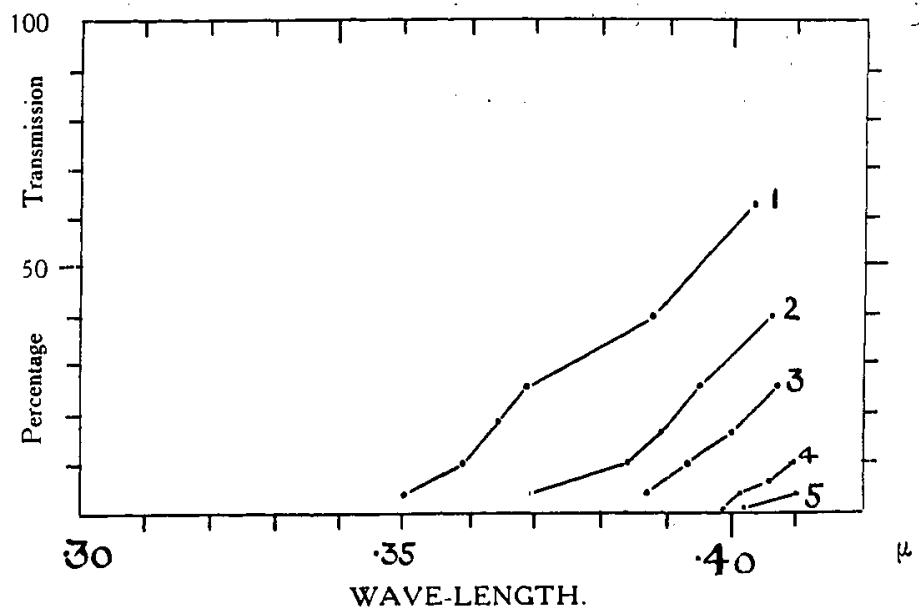

ULTRA-VIOLET.

limit is in the visible spectrum. The colour is a pleasant green, becoming more yellow with increasing density. Note the shift of maximum transmission in the visible. 
It would be interesting to know why Nos. 1, 2, and 3 are so markedly different from the rest in the region $1 \mu$. From the position of the maxi-

FIEUZAL GLASSES.

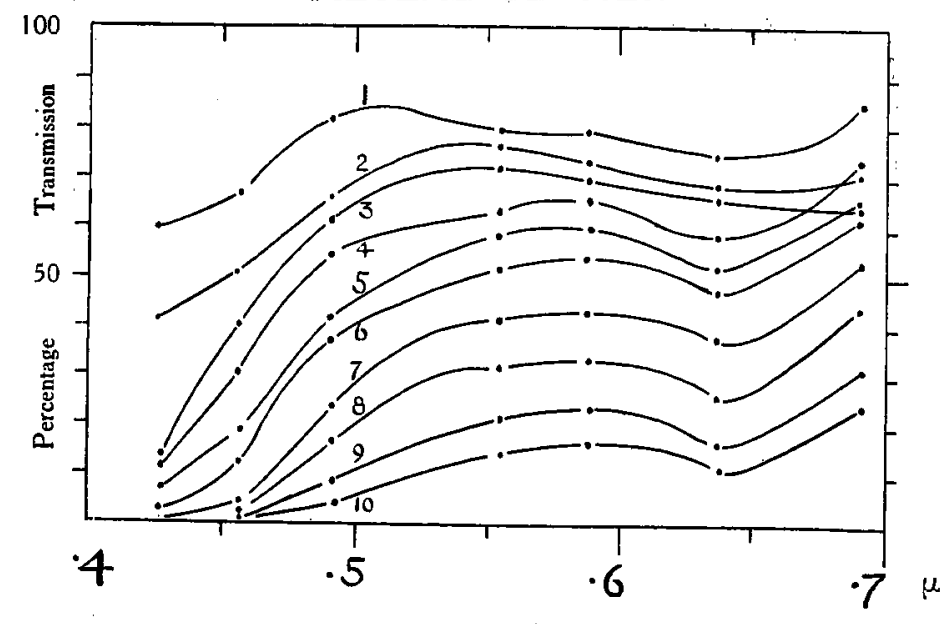

WAVE-LENGTH

VISIBLE.

mum in the visible, and the evident absorption band at $1 \mu$, it looks as if copper or iron had been used in these. The characteristic of chromium glasses is their increase of absorption about $.65 \mu$.

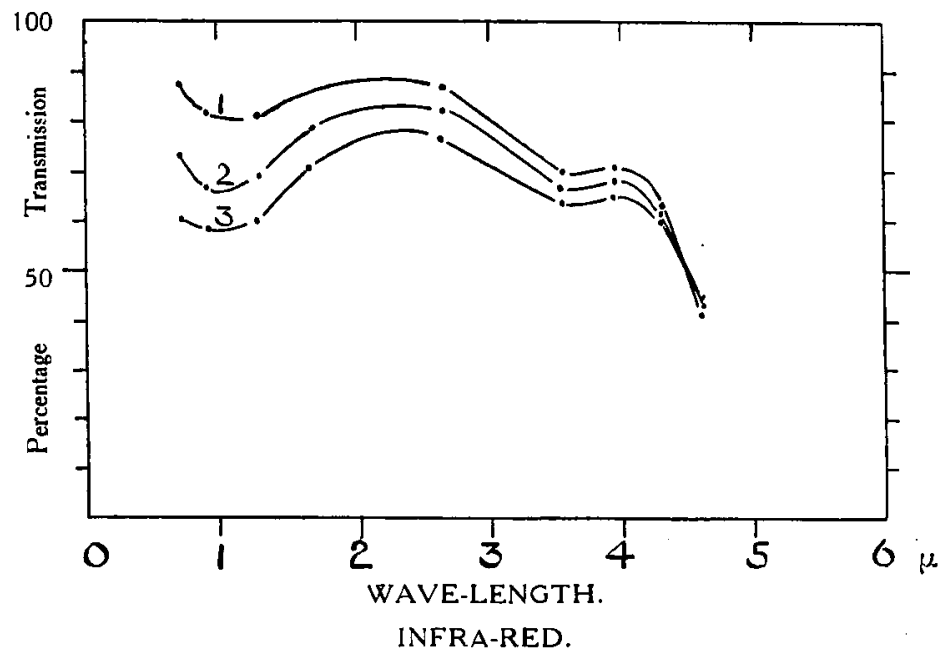


Note the gradual approach of the curves to the same point at long wavelengths in the infra-red. Little absorption is effected in this region.

FIEUZAL GLASSES.

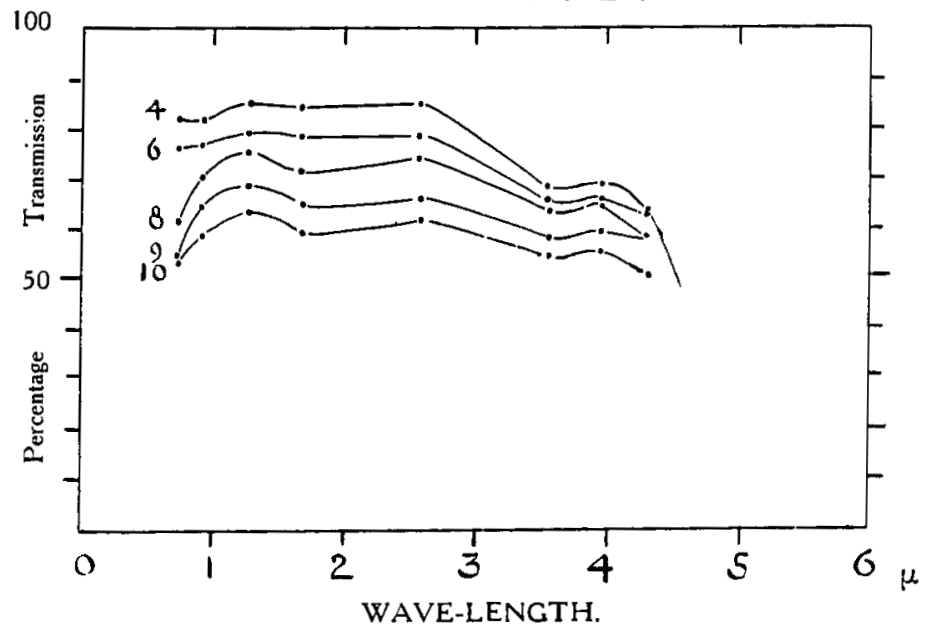

INFRA-RED.

Hallauer Glasses.-The effect of thickness is very marked in the ultra-violet. The transmission in the visible is very similar to that of HALLAUER GLASSES,

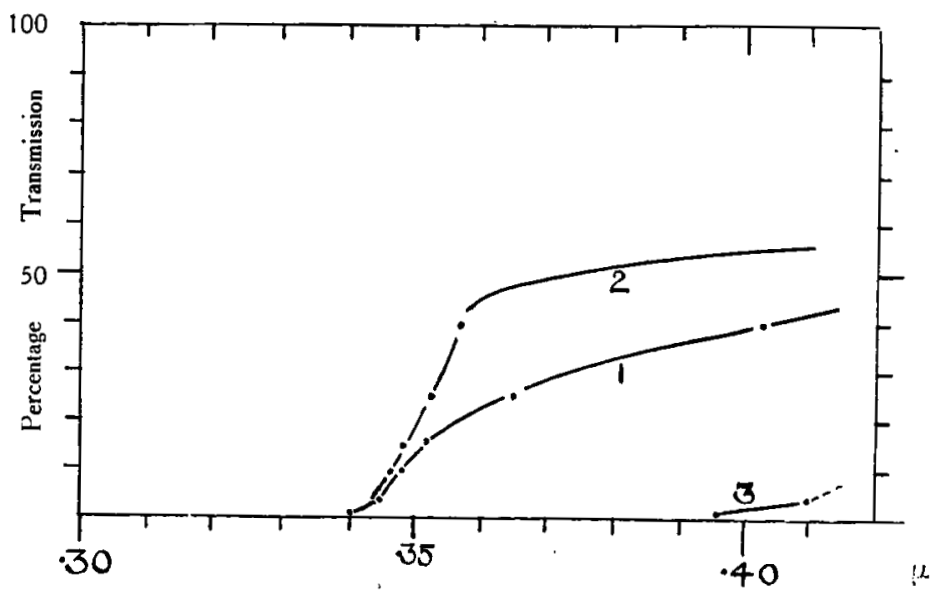

WAVE-LENGTH.

ULTRA-VIOLET. 


\section{Mr. L. C. Martin}

the Fieuzal series. There is no marked infra-red absorption beyond that due to the glass itself. The "light green" (No. 6) is more than twice as thick as the Hallauer tints, and shows greater absorption at long wavelengths.

HALLAUER GLASSES.

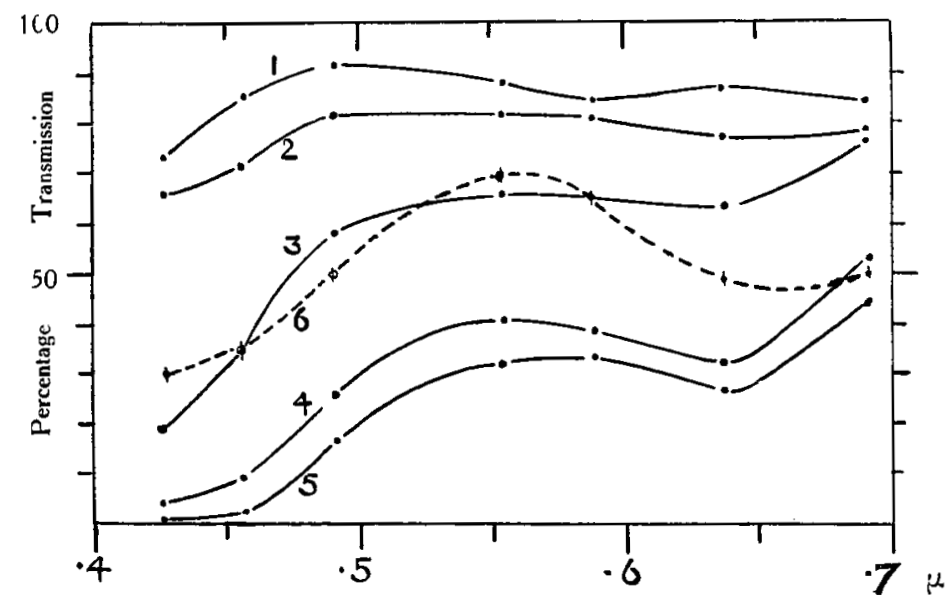

WAVE-LENGTH.

VISIBLE.

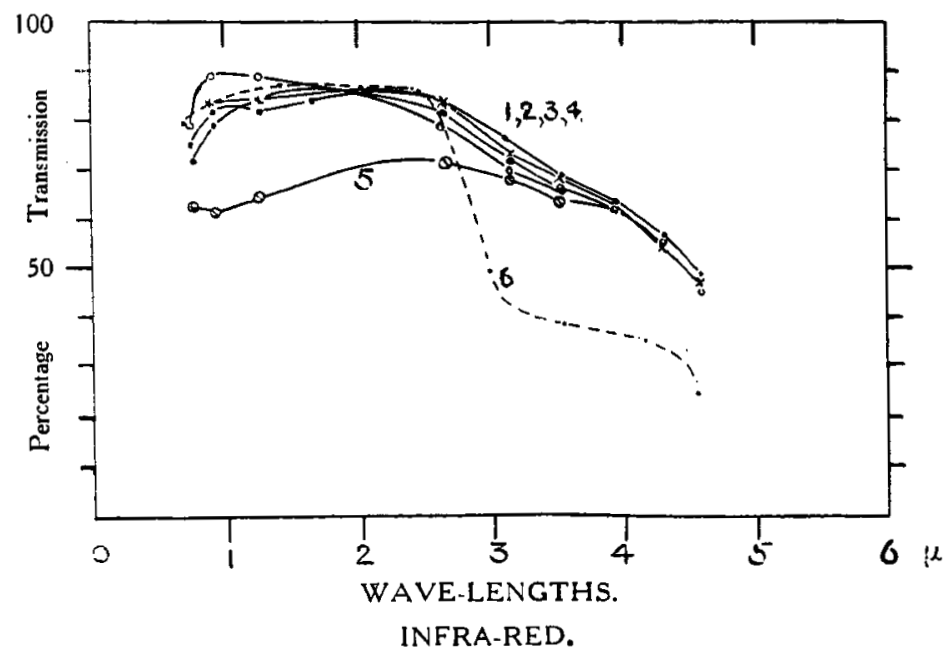

1, 2, 3, 4, \& 5-Hallauer graded tints.

6-Spare glass (light green). 
Light Filters for Eye Protection.

"CROOKes" 202.-This contains ferric iron and cobalt. The maximum absorption seems near $1.3 \mathrm{k}$ in the infra-red. The limit in the ultra-violet is $.352 \mu$, but this is with a fair thickness. The infra-red

CROOKES' GLASSES.
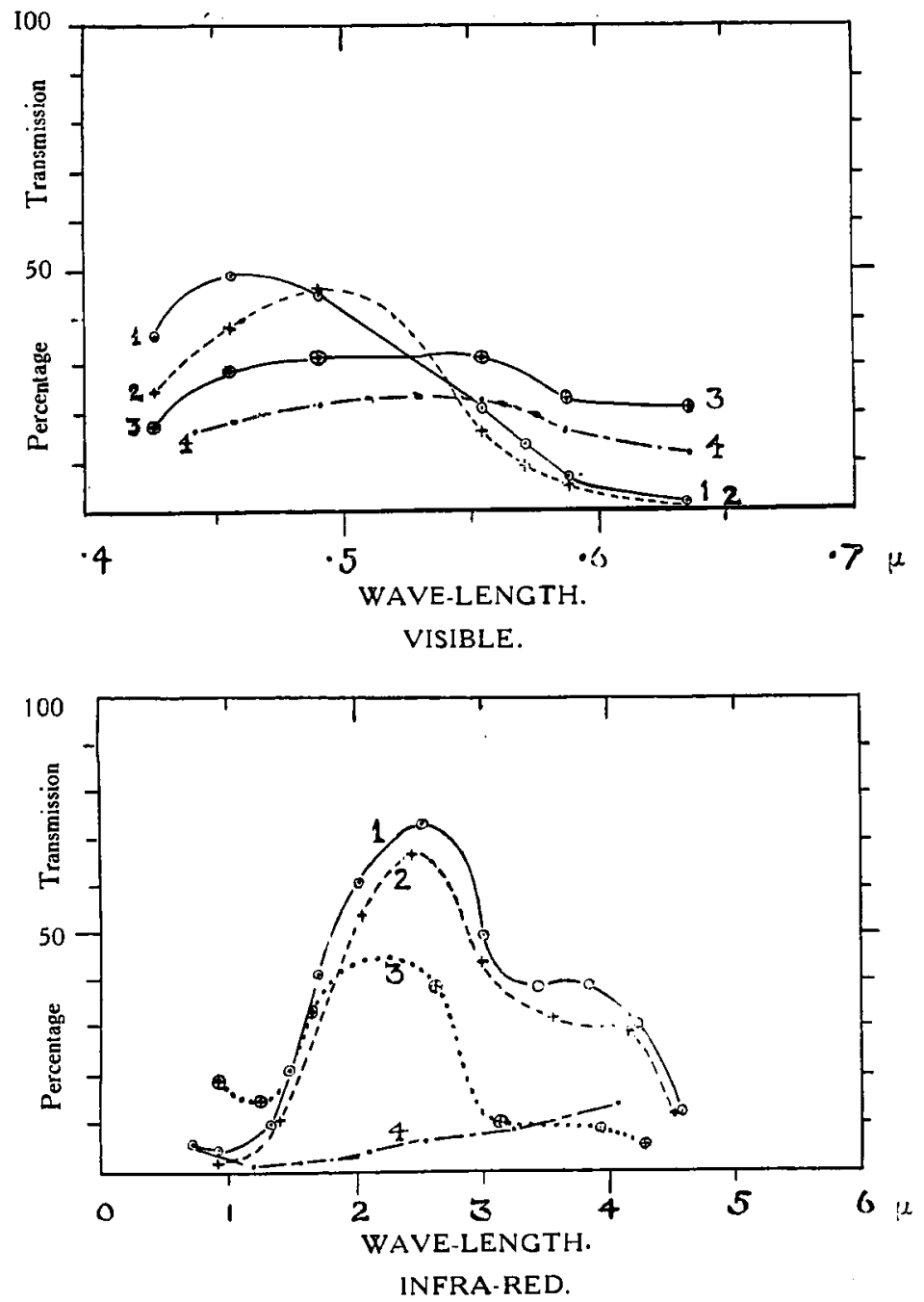

1. Signal Green.

3. Crookes' 202.

2. Ditto.

4. Ditto. 246. 
absorption is good compared with most other glasses, and keeps the transmission down between 1.5 and $3.0 \mu$.

"CROokes" 246.-The absorption band at about $1.3 \mu$ is very strong, owing, presumably, to considerable amounts of ferrous iron. This glass stops practically all the infra-red, while transmitting about 20 per cent. of visible energy. It is not very heavy in colour, and absorbs the ultraviolet very well.

Signal Green.-Results for two specimens are shown. The colour of one was deeper and more blue than the other. The chief colouring agent used for " signal green " is cupric oxide, and a characteristic absorption at about $1.0 \mu$ is shown. This is not so intense as the ferrous iron absorption, but would make it a very useful glass for wear in sunlight, as the band is in a region of great heat energy in the solar spectrum.

TINTS YELLOW TO RED.

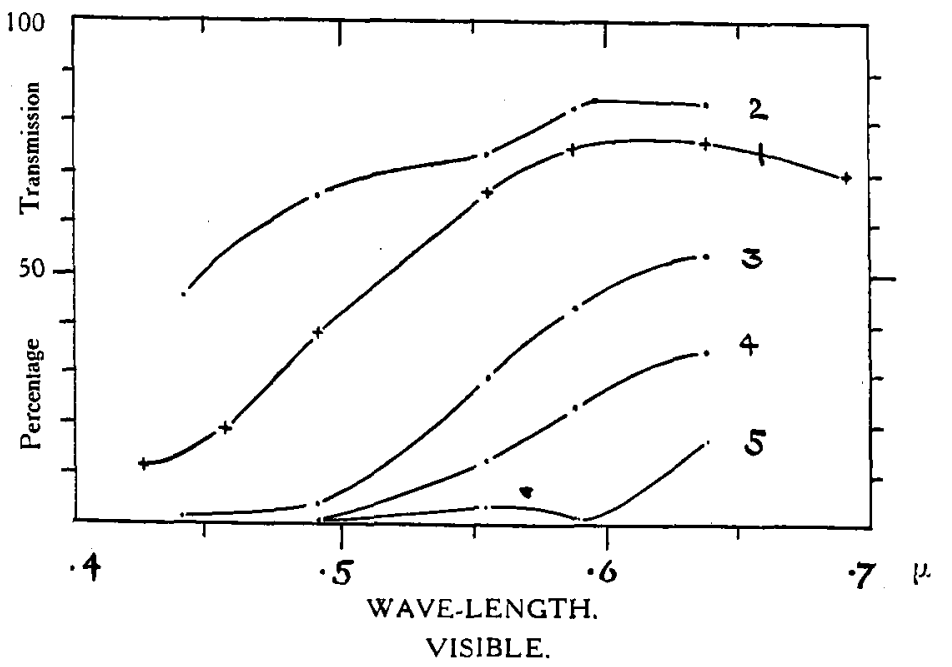

YELLOW RED SERIES.-The lightest of this series transmits well down into the ultra-violet although reducing the intensity. The others have a maximum transmission at the longer wave-lengths in the visible. None of the series show any particular absorpicion in the infra-red. 
Light Filters for Eye Protection.

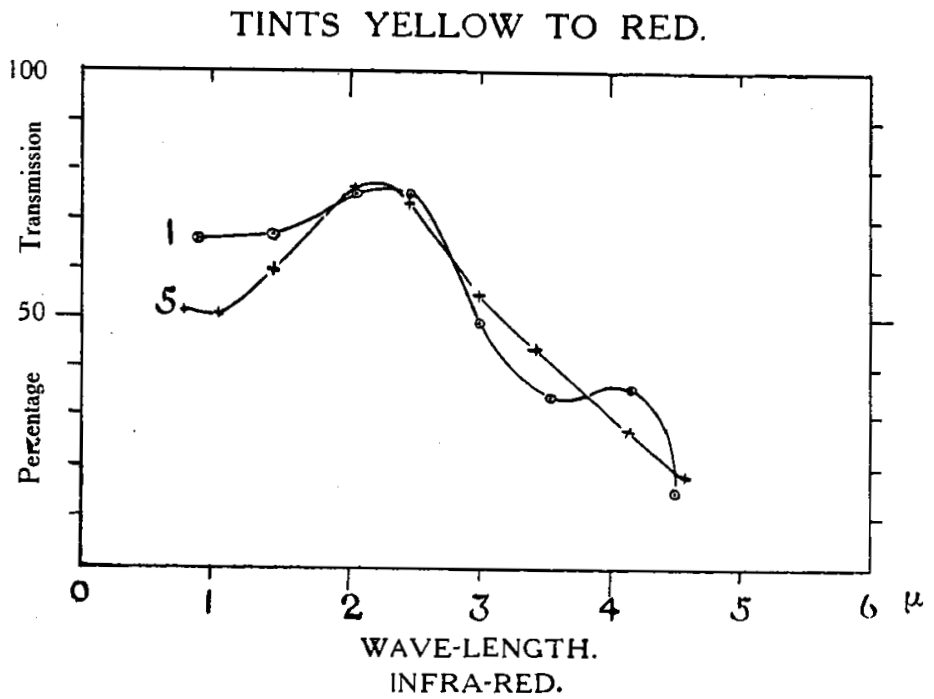

Celluloid Filters (Dyed). - The behaviour of these is very similar to that of glass. Strong absorption at about $3: 2$ is shown by many organic and other compounds, notably by water, and alcohol. The transmission

CELLULOID COMPOSITION FILTERS (Dyed).

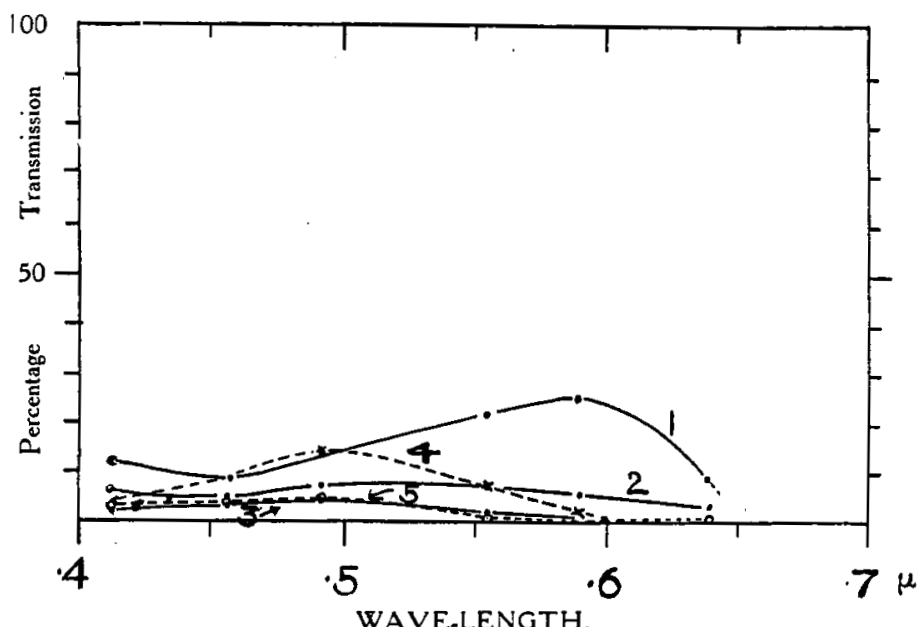

VISIBLE. 
in the visible and ultra-violet is small, although the limit is at a somewhat short wave-length. The collodion coated gelatine alone shows considerable absorption in the infra-red.

There are a few special devices which may provide useful filters. Metallic films on glass are the chief of these. A gold film has an almost uniform transmission, except in the green, where the transmission rises. It is thus possible to get a film reflecting nearly all the infra-red and visible, except in this region. The ultra-violet is similarly reduced. The difficulty of making such films which, for gold, must

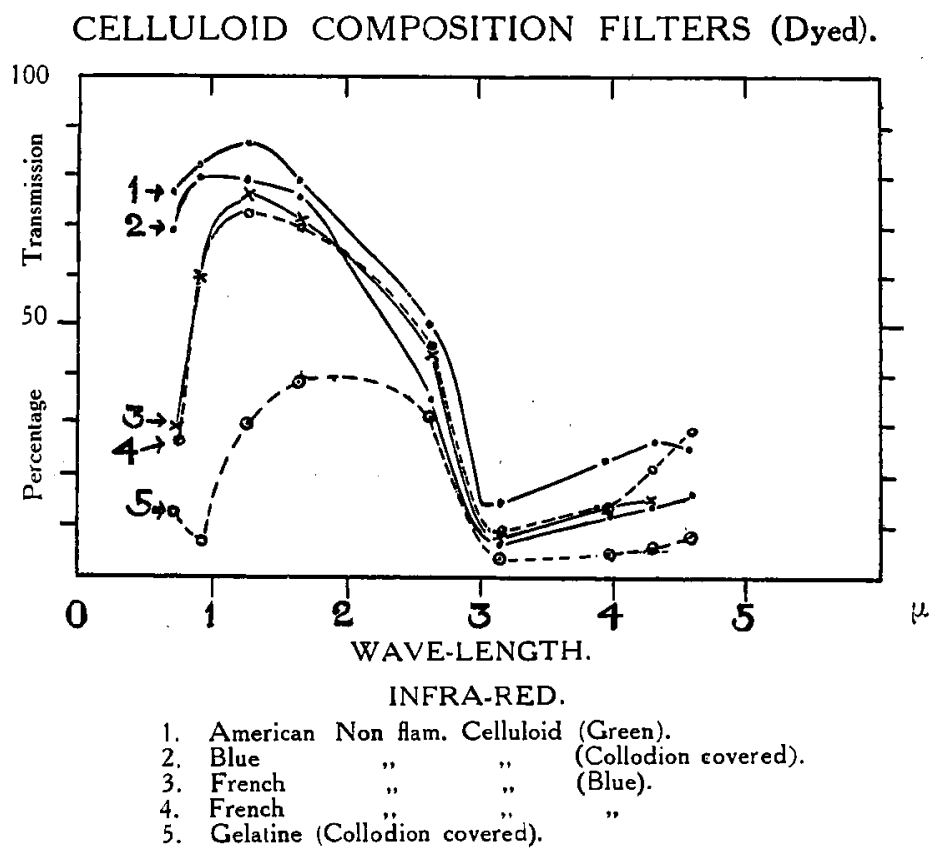

be done by kathode bombardment, is the chief factor against their common use. They would have to be between two plates of glass, but would make ideal heat and glare protectors, as most of the energy would be reflected and not absorbed, thus tending to keep the glass cool. Silver films act in nearly the same way, and can be chemically deposited. The colour of these is generally slightly blue, and they transmit fairly well between $.33 \mu$ and $.29 \mu$. A silver film, however, makes a very agreeable " neutral" eye glass. The ultra-violet transmission would not be against it as the glass on which it would be mounted could easily be chosen so as to annul the effect. If a silver film transmits 
10 per cent. of the light it will also transmit slightly less than 10 per cent. of the infra-red. It seems that these films would be preferable to glass for welding operations, \&c., as they cut down light and heat at the same time. Most ordinary coloured glasses transmit well in the infra-red. Platinum films are another alternative; they can also be chemically produced, and, further, they can be burnt into the glass. They absorb more radiation than silver or gold, and reflect less at the shorter wavelengths.

Another possible filter suggested by the work of Sir W. Crookes is found in black biotite or coloured mica. Thin films of this transmit a pleasant brownish green light, and have considerable absorption in the shorter infra-red and violet regions. Such films would also need protection in use.

COMPARISON WITH THE WORK OF SIR W. CROOKES 5 .-Limits of transmission in the ultra-violet were obtained by Sir W. Crookes with a source giving continuous spectrum, and a spectrograph giving greater dispersion. With the iron arc and a smaller spectrograph the limit found tends to be at $a$ shorter wave-length, and a definite meaning has now been assigned to it by quantitative absorption work.

In the visible region, Sir W. Crookes gives the luminosity of trans mitted light as measured by a Chapman Jones Opacity Meter, whereas this paper gives a measure of the percentage energy transmitted over a certain range of wave-length, an entirely distinct result.

In the infra-red an "integrated " result was found by using the energy transmitted by black biotite. The transmission of this substance in the infra-red, as shown by results recently obtained with the apparatus described in this paper, varies considerably with the nature and origin of the specimen. A few results have already been given by Kënigsberger ${ }^{17}$. Generally it absorbs heavily in the visible and infra-red up to about $1.5 \mu$ or $2.8 \mu$, depending on the variety tested. Maximum transmission is about $3.6 \mu$. The exact form of the transmission curve is being investigated, but it will be seen that such a filter in conjunction with a Nernst glower (maximum energy at $1.2 \%$ ) will tend to give a fairly even radiation in the infra-red, although the results must not be expected to corresspond exactly to those given in this paper, which express the percentage energy transmitted over a given range of wave-length.

It is hoped that these results may be of some use to those using or manufacturing anti-glare glasses. In conclusion, I desire to thank Prof. Fowler, F.R.S., for his valuable advice throughout the work, and Miessrs. W. Bradfield and C. Gregory, B.A., for their assistance with some of the experiments. 


\section{References.}

(1) Lummer and Pringsheim. Congres Internat. de Phys. Vol. II. p. 78.

(2) Langley. Chem. News, 43, 6, 1881.

(3) E. K. Martin*. Proc. Roy. Soc. B., LXXXV., 1912, p. 319.

(4) I.E.S. Amer. Report, No. 12, On Glare. 1914-15, p. 37.

(5) Sir W. Crookes. Phil. Trans. A. Vol. 214, 1914.

(6) Kerr. "Effects on Eye of Brightness and Contrast." Illuminating Engineering Society. February, 1917.

(7) Herman. Geometrical Optics, p. 214.

(8) Rubens. Handbuch der Spectroscopie, Kayser, Band IV., Pg. 507.

(9) A. Hilger, Ltd. Catalogue of Spectrophotometers.

(10) Howe. Physical Review. December, 1916.

(11) Abney. "Researches in Colour Vision."

(12) H. Rubens. Rapp. du Congres. Intnat. de Physique II., p. $141(1900)$.

(13) Coblentz. Investigations of Infra-red spectra. Carnegie Inst. Pub. 35.

(14) Zsigmondy. Absorption of Light in Coloured Glasses. Ann. d. Phys. 4, 60, 1901;

(15) Encyc. Britt. " Vision."

(16) Bunsen \& Roscoe. Pogg. Ann., 235-363. 1857.

(17) Kënigsberger. Ann. der Phys, 61, 687. 1897.

* Other literature on this subject :-

Hallauer.--Ueber die Absorption Kurzwelligen Licht durch die mensliche

Linse. Klin. Monatsbl. f. Augenheilk, Dec., 1909. vol. 47, p. 721.

SCHANZ AND STOCKHAUSEN.-Absorplion Spectra of the Media of the Eye.

Arch f. Ophth. 1908, vol. 69, pg. 1. Arch. f. Ophth. 1909, vol. 73, p. 184.

SORET.- Sur la transparence des milieux de l'œeil pour les rayons ultra violets.

Compt. Rend. 1879, vol. 88, p. 1,013.

\section{Additional Note.}

Since the writing of this paper, further work has been done on the ultra-violet spectrophotometer method. The transmissions of several biotite films in the visible spectrum were photographically measured with extreme care in this way, and the results were compared with those obtained with the Abney apparatus. It was found that perfect agreement existed between the results when transmission was assumed proportional to the ratio of sector openings, as is stated by Professor Howe. 
Further tests have been made on the transmission of neutral glasses, in which it was found that practically all specimens showed a remarkable increase of transmission at the extreme violet; some specimens about $1 \mathrm{~mm}$. thick transmit the ultra-violet between $.3 \mu$ and $.4 \mu$ practically as well as ordinary glass; only heavily coloured glasses show absorption worthy of note. At the red end of the visible spectrum also, transmission rapidly increases. These effects throw some light on the apparent discontinuities in some of the earlier curves.

$$
\text { July, } 1917 .
$$

$$
\text { L. C. M. }
$$

\section{DISGUSSION.}

Mr. W. A. DiXEY said the paper was a rather difficult one to discuss without a little further consideration. It touched on points which were of very great interest to many present, and they all ought to be very grateful to Mr. Martin for putting the paper together. He was a little doubtful as to whether the curves which had been exhibited on the screen were particularly applicable to the everyday requirements of Opticians in supplying spectacle lenses; what was really required was an estimate of the definite physical effect of the several differing intensities of radiation. In the diagrams given one would have wished that the thickness, and also the surface, of the various glasses compared should have been similar in the different specimens, because those factors would affect the results enormously.

Mr. MARTIN said those details were given in the paper.

Mr. DIXEY, continuing, said he had been interested in Mr. Martin's allusions to possible eye-strain in using instruments. $\mathrm{He}$ appeared to attribute the strain to possible want of clearness of definition. A spectacleman, or an Optician, however, perhaps saw the maiter a little more clearly than a laboratory experimenter. It appeared, for instance, to him (Mr. Dixey) that it was mainly a question of accommodation. When using a binocular instrument the question of accommodation was complicated by that of convergence. One ought to realise that an exact correlation, whether normal or created by habit, existed between the two functions, and if that was not carefully guarded in the adjustment of the instrument, eye trouble was sure to follow; it might be called strain, confusion, nausea or any other name. In a monocular insirument the main thing to remember was that the accommodation could be strained in only one direction. He had likened it very often to a hinged door. If there was over-focus of the instrument, beyond the one point of the exact focus, and the rays were unduly converged, the accommodation of the eye could not follow; it was up against the jamb of the door. But if the instrument was under-focussed, so as to produce 
diverging rays, then the accommodation would adapt itself to that underfocus, and if one continued to use an instrument like that, sight might be easy and exact, but eye-strain would result. He was aware that his criticism of the paper was very inadequate, but he did not like to say anything further upon the subject of the use of different glasses and their effects on the eye without studying the paper, which he should take an opportunity of doing as soon as it was printed.

Mr. T. SMITH wished to ask Mr. Martin whether he had stated in his paper the effects on the eye for which he was seeking protection-whether, for instance, he was seeking to exclude radiation which caused the crystalline lens to become opaque, or produced an injury to the retina, or resulted in some other damage to the eye. He would also like to ask whether the results which Mr. Martin had tabulated referred to the total loss of light in the different specimens, or whether he had subtracted the loss due to reflection. It would in any case, he thought, be useful to state what approximately were the refractive indices of the glasses, with the different wave-lengths, so that one effeci might be separated from the other, or the two added together, whichever way he had put them round. Furiher, was it the case that in the first and third diagrams shown on the screen the results obtained in the visible spectrum were discontinuous from those for the ultra-violet and infra-red? From the brief inspection possible while the slides were shown he thought there were appreciable discontinuities.

Mr. Hughes asked if Mr. Martin's experiments could be used for the standardisation of tints. As far as he knew, there was no definite standard. He was of opinion that tinted screens could be used a great deal more for terrestrial observations than they were.

Mr. H. R. Fairbanks thought the Society was much indebted to Mr. Martin for having brought forward this subject, and for the way in which he had plotted out the curves of the different glasses. If they set to work to investigate these curves in the way Mr. Martin had shown them, it would be very helpful in the direction of getting a clearer idea of the properties of coloured glasses. He sympathised with Mr. Dixey in his remark that the paper required careful study before it could be criticised in detail. There was one kind of glass in which he was intensely interested, to which he thought Mr. Martin had scarcely devoted so much attention as it deserved. He referred to signal green glass. He considered this a very valuable glass indeed, and its action in the ultra-violet was peculiar. All microscopists knew that signal green glass formed a strong basis for a monochromatic screen. There was another point on which he would like a little further explanation. Mr. Martin had spoken about the absorption band at the $\mathrm{D}$ line in the Crookes glass. He had not quite caught Mr. Martin's explanation, but he thought that that absorp. tion band in the Crookes glass was one of the most valuable properties 
of the glass. It would be found that the absorption band at the $\mathrm{D}$ line was in every piece of Crookes glass which was examined. Whether or not this was due to water conditions, he would not like to say, but he rather doubted it.

Mr. S. A. WiLlmotT remarked that when one looked at the moon through a powerful telescope, there was a feeling of discomfort, whereas when observed with the naked eye there was no such feeling. In the former case the image was not any brighter on the eye, but it was very much larger. He did not know whether Mr. Martin could explain why this discomfort should be experienced on viewing the moon through a telescope.

Dr. R. Mullineux WalmsLey said the historical work embodied in Mr. Martin's paper would be a great convenience to many who were not in a position to refer to the original authorities. Like other speakers, he felt it difficult to attempt to criticise in detail a paper so packed with information, especially as it had been read in abstract ; it was, therefore, only possible for an auditor to deal with odd points which had occurred to him during the reading of the paper.

One such point which had struck him (Dr. Walmsley) was this. The members of the Optical Society had a great respect for the heterogeneity of glass, its composite nature, its grading, and its methods of manufacture. What they would like to know from Mr. Martin-though where so much work had already been done, involving very great labour, one hesitated to ask for more-was the effect of the colouring matter itself upon absorption. In order to get at that, it would be necessary to compare the absorption of the actual glass obtained from the same melting before the addition of the colouring matter with the absorption of the glass obtained after the colouring matter had been added. The prospect of having to do all this in detail was something awful, and he did not know whether some of the glass-manufacturing experts might not say it was impossible.

Then another quite minor suggestion. In the first slide shown by Mr. Martin, he had drawn attention to the maxima along the spectrum, and it occurred to him (Dr. Walmsley) that if a dotted line were drawn through these maxima it would make the slide much more effective.

Mr. P. F. EVFritT desired to ask Mr. Martin a question with regard to the stained films. Many of the dyes used for staining films had a fluorescent action, and the question occurred whether pure stains or mixed stains were used for such purposes, and whether the order of the stains might not make quite a difference in the transmission spectrum.

Mr. RHEInBERG said he would like to ask Mr. Martin whether the question of screens for comfort and for visual acuity, \&c., had received consideration from a somewhat different standpoint, viz., the evolutionary 
standpoint, as it seemed to him that it led directly to certain inferences. It might be taken for granted that the eye, by the process of evolution, was naturally adapted to ordinary light-sunlight or skylight-and, therefore, that the radiations in their normal proportions which occurred in such light would not be harmful, whereas any abnormal excess of any of these radiations, or the presence of other radiations, might a priori be taken to be likely to be more or less detrimental, and where they occurred in artificial lighting, \&c., it would seem safer if the screen eliminated them.

Then again as regards screens for acuity of vision. The process of evolution had determined the sensitiveness of the eye for colours, the normal curve showing a maximum in the yellow or greenish yellow, and it might therefore be assumed straight away that this would be where the geatest visual acuity would be found. As owing to the well-known chromatic aberration of the eye, the different colours were not simultaneously in focus, the screen would be one which chiefly transmitted this region of the spectrum and cut down the other colours. He believed that in practice nearly all screens for visual acuity would be found to be yellow or greenish yellow.

Dr. WALTER RoSENHAIN regretted that having unfortunately arrived late he had not heard the whole paper, He was, however, very much interested in the part he had heard, and he thought the paper would prove valuable, as much for the methods described as for the results. He could not, of course, attempt to criticise the paper, but wished to mention two small points which, though not directly connected with the paper, nevertheless had reference to its subject. First of all there was the very wide subject of the choice of absorption glasses. He had had in 1914 the privilege of a voyage through the cropics and back again in connection with the British Association's visit to Australia, and, through the courtesy of Messrs. Chance, he had been able to try on that occasion two pairs of glasses made of Crookes glass, one very lightly and the other heavily tinted. He had never found any use for the heavily tinted pair, but the light pair had proved most extraordinarily comfortable-far more so than a pair of ordinary tinted glasses which he had also had with him for the sake of experiment. Unfortunately his eyes were distinctly sensitive to bright light, and he had found the light-tinted Crookes glasses extremely comfortable and perfectly neutral. He did not know how it was to be accounted for, but they certaintly had produced the desired effect. Then with regard to the use of tinted glasses when observing with an instrument for a length of time, no doubt this would lead to considerable rest and comfort, and there was a very simple way of doing it. With very little practice it was, he thought, perfectly possible to use any optical instrument, with the exception, perhaps, of microscopes 
employing very high power eye-pieces, with any pair of spectacles, and of course the glasses could be of any colour one preferred. In this way it was possible, in using a telescope, to secure the desired ease and comfort without any special attachment whatever.

The PRESIDENT said there was one small matter to which he wished to direct attention before calling upon Mr. Martin to reply. Mr. Willmott had pointed out the fact that the glare of the moon through a telescope produced discomfort, while no such effect was caused by looking at that luminary with the naked eye. In connection with that he might mention one of the most extraordinary, and still unsolved, of optical problemsthat of Herschell. Within a short distance of Herschell's observatory was a village church and clock by which the time could be seen with the unaided eye in the daytime. At night-time, when so dark that the church itself was invisible, Herschell found that by the use of his reflector he could not only see the church, but the time indicated by the clock itself. Now it was of course an axiom in optics that the intrinsic brightness of a retinal image, no matter what optical aid was employed, could never exceed the intrinsic brightness of the retinal image produced by direct and unaided vision.

Mr. S. D. Chalmers said that the problem in question had probably been solved by the observations of Patterson and Dudding on the visibility of small sources. The results and some considerations of the speaker were included in a discussion on "Visibility" at the Illuminating Engineering Society.*

\section{AUTHOR'S REPLY.}

Mr. Martin, in replying, said that, with regard to the definition in the field of view of a telescope, accommodation would enable the image to be focussed if the instrument were slightly out of adjustment, but the bad definition to which he had referred was chiefly due to residual chromatic aberration; this became very trying when observing, say, a smali white flag for signalling purposes.

The chief effects of ultra-violet rays were discomfort, inflammation of the conjunctiva, and other phenomena, with opacity of the cornea in extreme cases. Infra-red rays were also liable to produce cataract with long-continued exposure.

Tinted glasses could be exactly standardised by obtaining the absorption curves, but difficulties might be experienced in exactly reproducing a glass as the tint was liable to vary somewhat in different meltings.

"The Illuminating Engineer, p. 210, No. 5, Vol. VIII., May, 1915. 
Signal green was doubtless a valuable glass, and fuller details were given in the paper. With regard to the absorption band in the yellow, in Sir W. Crookes' spectacle glass, this was due to Didymium, which he had understood to be an unnecessary impurity.

Strain in observing the moon through a telescope was probably due to lack of adaptation. As far as retinal glare was concerned, the size of the source of light was of great importance. A small object, such as a condensed electric spark, could be looked at without discomfort, although it might give a very strong radiation. The same applied to a distant arc lamp. Thus the direct observation of the moon without a telescope would affect a very small area of the retina, and would not produce discomfort. When a telescope was used, an intense light was thrown on to a comparatively large area of the unadapted retina, and glare resulted. The observation was less trying in daylight when the eyes are adapted to stronger illumination.

He agreed with Dr. Walmsley that it would have been desirable and interesting to have given for each glass the absorption, with and without the colouring oxides, but the glasses tested were commercial samples of unknown composition. The base was generally a simple soda lime glass, the absorption of which has been thoroughly investigated. Such results were given in Hovestadt's "Jena Glass."

The testimony of Dr. Rosenhain as to the value of "Crookes" glass ; was extremely interesting, and doubtless the experience of such a skilled observer was a valuable indication of the utility of the glass. He did not think, however, from knowledge of particular cases, that such glasses were a panacea for relieving eye-strain and glare, although they might be extremely useful in special cases.

Mr. Everitt's remarks on celluloid filters were of great interest. He had had several examples of stained films sent him which were very efficient for their particular uses. $\mathrm{He}$ had no experience of the preparaicion of these, but at first sight it did not appear that the mere order of the stains should affect the absorption.

From personal experience in Gallipoli, he fully realised the strain in the use of a telescope for prolonged periods under intense illumination. This was a serious matter, and he hoped that the few results in the paper would lead to some investigation of the subject.

Good definition doubtless contributed greatly to comfort in vision, but the increase in acuity when using a relatively monochromatic glass as against a neutral glass was hardly sufficient to give any appreciably greater comfort. The increased contrast may be more satisfactory to the eye. 
With regard to the President's remarks, it was of great interest to hear that some explanation had been offered of the curious effect noted by Herschell. The explanation of the visibility of stars from the bottom of a deep shaft was a somewhat similar problem.

Mr. T. SMIth : May I ask whether that is a fact?

The President : I may say I put that problem to the Astronomer Royal some time ago, and he would not commit himself.

Mr. Martin, continuing, said that although some light had been thrown on these questions, they did not appear to be fully explained.

In reply to Mr. T. Smith, the results given expressed the actual transmission of specimens after reflection and absorption. In calculations of the transmission of other thicknesses for technical purposes, it was sufficiently accurate to assume a mean value for the refractive index and consequent reflection.

There were two small regions at each end of the visible spectrum $.40 \mu-.438 \mu$, and $.69 \mu-.76 \mu$, in which it was difficult to obtain measures of absorption with his existing apparatus. In some of the earlier experiments these intervals were wider, and unfortunately the measurement at about $.76 \mu$ with the infra-red apparatus was the most uncertain, as the galvanometer deflections were very small at this point. Some of the glasses tested had a somewhat rapidly changing transmission in these regions, especially green and neutral tints. Thus the curves did not always appear to join. The differing scales of wave-length must be remembered when looking at the results. 